This is the final peer-reviewed accepted manuscript of:

"Aggregation induced phosphorescence of metal complexes: from principles to applications"

L. Ravotto, P. Ceroni

Coord. Chem. Rev. 2017, 346, 62-76

The final published version is available online at: https://doi.org/10.1016/j.ccr.2017.01.006

Rights / License:

The terms and conditions for the reuse of this version of the manuscript are specified in the publishing policy. For all terms of use and more information see the publisher's website.

This item was downloaded from IRIS Università di Bologna (https://cris.unibo.it/)

When citing, please refer to the published version. 


\title{
Aggregation induced phosphorescence of metal complexes: From principles to applications
}

\author{
Luca Ravotto, Paola Ceroni* \\ Department of Chemistry “Giacomo Ciamician” and Interuniversity Center for the Chemical Conversion of Solar Energy (SolarChem), University of Bologna, Via Selmi 2, 40126
} Bologna, Italy

\begin{abstract}
A B S T R A C T
Metal complexes are the prototypes of phosphorescent materials, widely used in a range of optoelectronic and sensing applications. This review reports the most recent and tutorial results in the area of aggregation induced phosphorescence (AIP) of metal complexes, i.e. molecules that are weakly or nonphosphorescent in deaerated fluid solution and whose room temperature phosphorescence is switched on upon aggregation. The examples are divided into two main classes according to the AIP mechanism: (i) rigidification that causes a restriction of intramolecular motions as well as of structural distortion of the phosphorescent excited state and (ii) metallophilic interaction that brings about new electronic transitions compared to the isolated chromophores. The last section is devoted to a special class of molecules and supramolecular systems, in which metal complexation turns on phosphorescence of nearby organic chromophores, so that the metal complex is not directly involved in the phosphorescence process.
\end{abstract}

\section{Contents}

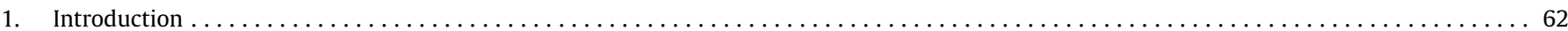

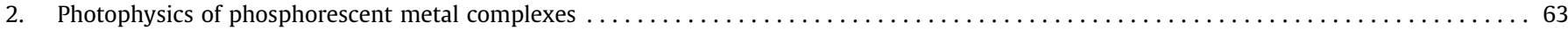

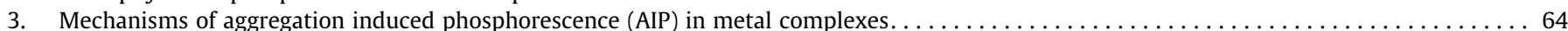

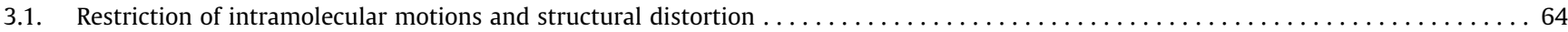

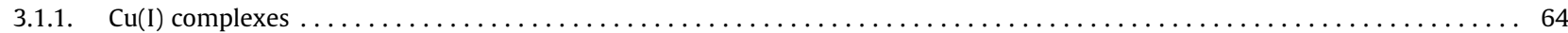

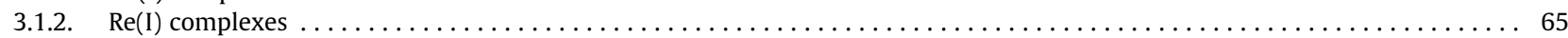

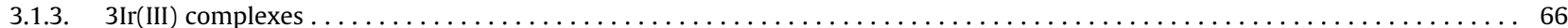

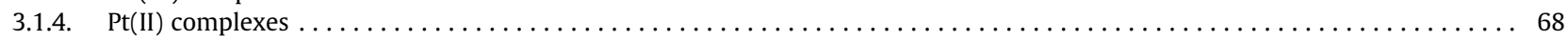

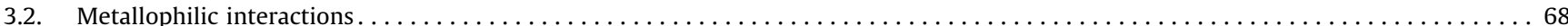

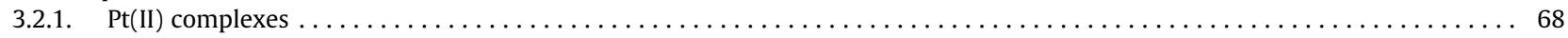

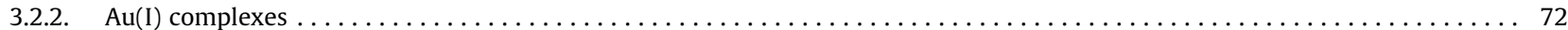

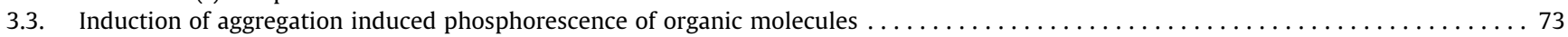

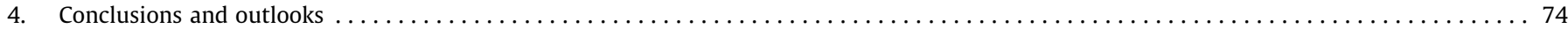

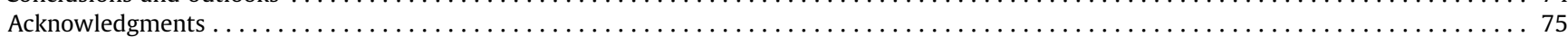

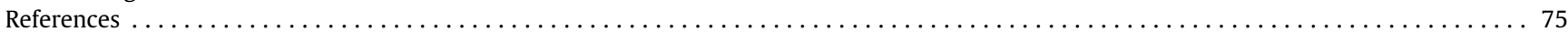

\section{Introduction}

Phosphorescence, the spin-forbidden radiative decay of an electronically excited state, has been known for a long time. In 1941

\footnotetext{
* Corresponding author.

E-mail address: paola.ceroni@unibo.it (P. Ceroni).
}

Lewis and his coworkers first suggested that the long-lived phosphorescence of fluorescein in rigid media derives from the lowest triplet state [1]. The first unequivocal demonstration of the fact that phosphorescence originates from a triplet state was made by Lewis and Calvin in 1945 [2]: they demonstrated that the phosphorescent state of fluorescein in a boric acid glass at room temperature is paramagnetic. 
Although the first studies were devoted to organic molecules, phosphorescence is usually regarded as a property of metal complexes because the presence of a heavy metal atom increases the spin-orbit coupling and favors spin-forbidden radiative and nonradiative decays of electronically excited states. Indeed, phosphorescent metal complexes are widely used in technological applications, like organic light-emitting devices (OLED) [3], light-emitting electrochemical cells (LEC) [4], and luminescent sensors [5] of pressure and dioxygen, for example.

Recently, it has emerged a great interest on metal complexes that are weakly or non-phosphorescent in deaerated fluid solution and whose room temperature phosphorescence is switched on either by rigidification of the matrix (e.g. crystallization) or by aggregation and electronic interactions of the molecules among themselves. Some authors distinguish between "aggregation induced phosphorescence" (AIP), referred to a compound that is non-emissive as isolated molecule in solution and emissive in the aggregated form, and "aggregation induced phosphorescence enhancement" (AIPE), for a compound that is weakly emissive as monomer and more emissive as an aggregate. Since the underlying phenomenon is identical in the two cases and the distinction between a non-emissive and a weakly emissive compound is somehow arbitrary, we will describe examples of both classes and we will use the AIP acronym in this review. Many examples of this phenomenon has been studied in the past, for example in the case of metallophilic interactions in $\mathrm{Au}(\mathrm{I})$ or $\mathrm{Pt}(\mathrm{II})$ metal complexes, but they were not named as aggregation induced phosphorescent molecules, so that it is difficult to have a complete overview of the very vast area of this research. The present review is thus devoted to provide the reader with some basic concepts of photophysics of metal complexes, to discuss the designing principles to get AIP materials and to present recent and most relevant examples from a tutorial point of view.

Before presenting examples and their potential applications, it is worthwhile recalling a few elemental principles of electronic transitions in metal complexes with particular emphasis on phosphorescence and the parameters affecting its efficiency. Interested readers can refer to several books for a deeper discussion [6-9].

\section{Photophysics of phosphorescent metal complexes}

In order to simplify the picture and consider the effect of light excitation, schematic molecular orbital diagrams such as that shown in Fig. 1 for an octahedral complex may be used. Molecular

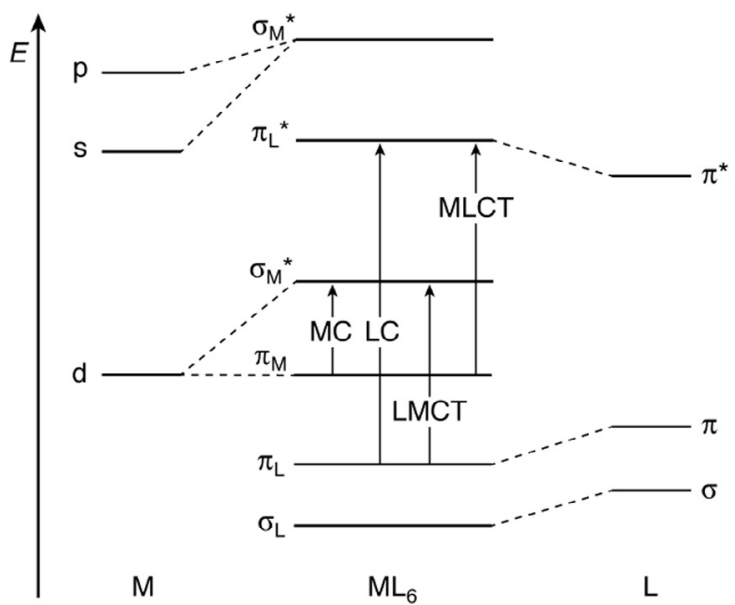

Fig. 1. Schematic molecular orbital diagram for an octahedral complex of a transition metal. The arrows indicate the four types of electronic transitions (only the lowest energy transitions are represented) based on localized MO configurations. orbitals of metal complexes are classified as centered either on the metal or on the ligand according to their predominant contributions. As a consequence, electronic transitions are defined as follows: metal-centered (MC) transitions when an electron is transferred between two metal-centered orbitals, e.g. from $\pi_{\mathrm{M}}$ orbitals to $\sigma_{\mathrm{M}}^{*}$ orbitals; ligand-centered (LC) transitions when the involved orbitals are ligand-centered, e.g. $\pi_{\mathrm{L}} \rightarrow \pi_{\mathrm{L}}^{*}$; ligand-tometal charge-transfer (LMCT) transitions e.g. of type $\pi_{\mathrm{L}} \rightarrow \pi_{\mathrm{M}}^{*}$; metal-to-ligand charge-transfer (MLCT) transitions e.g. of type $\pi_{\mathrm{M}} \rightarrow \pi_{\mathrm{L}}^{*}$. Fig. 1 is just a schematic representation and represents the lowest energy electronic transitions: for example, LMCT can originate from $\sigma_{\mathrm{L}} \rightarrow \sigma_{\mathrm{M}}^{*}$ transitions. The relative energy ordering of the resulting excited electronic configurations depends on the nature of metal and ligands. Low energy metal-centered transitions are expected for the first row transition metals, low energy ligand-to-metal charge-transfer transitions are expected when at least one of the ligands is easy to oxidize and the metal is easy to reduce, low energy metal-to-ligand charge-transfer transitions are expected when the metal is easy to oxidize and a ligand is easy to reduce, and low energy ligand centered transitions are expected for aromatic ligands with extended $\pi$ and $\pi^{*}$ orbitals.

If the ground electronic configuration is closed-shell, the ground electronic state is a singlet, usually denoted by $\mathrm{S}_{0}$. When an electron is promoted from one of the low-energy occupied molecular orbitals to a high-energy unoccupied orbital, singlet and triplet excited states occur in pairs $\left(S_{1}\right.$ and $T_{1}, S_{2}$ and $T_{2}$, etc.). Thus, the lowest excited state is a triplet state $\left(\mathrm{T}_{1}\right)$, i.e. a state having a different multiplicity from that of the ground state. This is always the case for organic molecules, but, for some transition metal complexes, the ground-electronic configuration contains degenerate orbitals which are not completely filled and, as a consequence of the Hund rule, the ground state has a multiplicity higher than one and intraconfigurational electronic transitions can occur (see e.g., $\mathrm{Cr}(\mathrm{III})$ complexes) $[6,10]$.

In the present review, most of the examples will deal with metal complexes featuring a closed-shell configuration and thus the ground state is a singlet $\left(\mathrm{S}_{0}\right)$ and the lowest excited states are singlet $\left(\mathrm{S}_{1}\right)$ and triplet states $\left(\mathrm{T}_{1}\right)$. The phosphorescence quantum yield $\left(\Phi_{\mathrm{ph}}\right)$, i.e. the ratio between the number of emitted photons and the number of absorbed photons, is the product of the efficiency of population of $\mathrm{T}_{1}\left(\eta_{\text {isc }}\right)$ by inter system crossing from upper lying excited states (e.g., $S_{1}$ ) and the intrinsic efficiency of phosphorescence $\left(\eta_{\mathrm{ph}}\right)$, i.e. the percentage of $T_{1}$ deactivating by phosphorescence:

$\Phi_{\mathrm{ph}}=\eta_{\mathrm{isc}} \times \eta_{\mathrm{ph}}$

To maximize the phosphorescence quantum yield, we need to maximize $\eta_{\text {isc }}$ and $\eta_{\text {ph }}$, both processes are spin-forbidden. The spin selection rules of radiative and non-radiative processes are valid to the extent to which spin and orbital function can be separated rigorously. Departures from this approximation are due to spin-orbit coupling, which mix electronic states of different multiplicity and increases as the atomic number of the atoms involved increases (for an atomic species, spin-orbit coupling is proportional to the fourth power of atomic number, $\mathrm{Z}^{4}$ ). This is the reason why most of the phosphorescent materials are based on metal complexes. The spin-orbit coupling is particularly high for metals belonging to the second and third transition series. The efficiency of the $\mathrm{S}_{1} \rightarrow \mathrm{T}_{1}$ intersystem crossing is usually close to unity and the quantum yield of fluorescence is close to zero. In addition, rate constants of both the $\mathrm{T}_{1} \rightarrow \mathrm{S}_{0}$ phosphorescence and the $\mathrm{T}_{1} \rightarrow \mathrm{S}_{0}$ intersystem crossing are much greater than in organic molecules. As an example, the different amount of spin-orbit coupling is one of the reasons why in a rigid matrix at $77 \mathrm{~K}$ (where bimolecular deactivation processes cannot occur) the lifetime of the lowest spin 
forbidden excited state of naphthalene is longer than one second, whereas the lifetime of the lowest spin-forbidden excited state of $\left[\mathrm{Ru}(\mathrm{bpy})_{3}\right]^{2+}$ is in the microsecond time scale.

Spin-orbit coupling is increased when the involved excited states are separated by a low energy difference (energy gap law) [11]. The energy separation between the singlet and triplet states of a given electronic configuration arises from the repulsion experienced by neighboring electrons and corresponds to twice the electron exchange integral $[11,12]$. When the electronic transition is MLCT or LMCT, the spatial orbital overlap is very limited, so that the singlet-triplet splitting is small. This is the reason why complexes showing low lying $\mathrm{CT}$ excited states display high efficiency of population of $\mathrm{T}_{1}$ excited state $\left(\eta_{\text {isc }}\right)$.

\section{Mechanisms of aggregation induced phosphorescence (AIP) in metal complexes}

In the present review, we will present examples in which phosphorescence quantum yield is strongly increased upon aggregation, i.e. upon going from isolated metal complexes in solution to aggregates in the solid state or in nanostructures dispersed in solution. The mechanisms of this effect can be divided into two main classes: (i) aggregation causes a rigidification of the metal complex both in the ground- and in the excited states; (ii) aggregation brings metal complexes in close proximity, thus facilitating metallophilic interactions.

The former mechanism can be explained as follows: packing chromophores in a crystalline or amorphous structure leads to a reduction of molecular motions with respect to the individual molecules in solution. The structural rigidity limits vibration (e.g., of long alkyl chains) or rotation (e.g., phenyl rings) of appended subunits and hinders structural distortion of the equilibrium geometry of the phosphorescent excited states. Both of these factors lead to a decrease of the rate of non-radiative processes, which deactivate the phosphorescent excited state and result in an increase of $\eta_{\mathrm{ph}}$ and thus of $\Phi_{\mathrm{ph}}$ (Eq. (1)).

It is worth noting that phosphorescence quantum yield in fluid solution is strongly reduced by bimolecular quenching processes. These are particularly important in the case of long-lived excited states, as in the case of phosphorescent excited states. Indeed, the kinetics of the bimolecular quenching process is described by the Stern-Volmer equation in fluid solution:

$\tau^{0} / \tau=\Phi^{0} / \Phi=1+\mathrm{k}_{\mathrm{q}} \tau^{0}[\mathrm{Q}]$

where $\tau^{0}$ and $\tau$ (or $\Phi^{0}$ and $\Phi$ ) are the lifetimes (or emission quantum yields) of the chromophore in the absence and presence of the quencher, respectively, $\mathrm{k}_{\mathrm{q}}$ is the quenching constant and [Q] is the molar concentration of the quencher [6]. For example, dioxygen, which is dissolved in $\mathrm{mM}$ concentration in air-equilibrated solutions, does not quench fluorescent excited states that are shortlived (ns timescale), but strongly quenches phosphorescent excited states. From Eq. (2), you can estimate that for a chromophore with $\tau^{0}\left(\mathrm{~T}_{1}\right)=10 \mu \mathrm{s},[\mathrm{Q}]=1 \mathrm{mM}$ and $\mathrm{k}_{\mathrm{q}}=10^{9} \mathrm{M}^{-1} \mathrm{~s}^{-1}$, the resulting phosphorescence quantum yield is ca. 10 times lower than $\Phi^{0}$.

The formation of aggregated structures limits the diffusion of dioxygen, thus suppressing this quenching pathway and increasing the phosphorescence quantum yield. This mechanism is common to all phosphorescent compounds, particularly for chromophores exhibiting long-lived phosphorescent excited states, and it will not be discussed in the following. To ascertain that this is not the main factor responsible for the observed AIP effect, one should compare phosphorescence quantum yield of the metal complex in deaerated fluid solution and in the aggregated state.
The mechanism based on metallophilic interactions is typical of metal complexes and it will be discussed with reference to the electronic and geometrical properties of representative metal ions.

In addition to the phenomena discussed above, phosphorescence of organic chromophores can be induced upon metal complexations: in this case, the metal complex is not directly responsible of the phosphorescence, but causes a rigidification/ interaction of the organic chromophores linked to it. Two representative examples will be illustrated in the last section.

For each mechanism, we report a selection of recent and tutorial examples with a brief description of the most interesting applications. The examples of each class are divided according to the metal ion (e.g. $\mathrm{Cu}(\mathrm{I}), \operatorname{Re}(\mathrm{I}), \mathrm{Ir}(\mathrm{III}), \mathrm{Pt}(\mathrm{II}), \mathrm{Au}(\mathrm{I})$ ), presented in order of increasing atomic number. A complete overview on all the metal complexes that exhibit AIP effect is out of the scope of this review: for examples, AIP metal complexes based on $\mathrm{Rh}(\mathrm{I})$ [13], $\mathrm{Pd}(\mathrm{II})$ [14], $\mathrm{Hg}(\mathrm{II})$ [15], $\mathrm{Bi}(\mathrm{III})$ [16], Os(II) [17] and $\mathrm{Ru}(\mathrm{II})$ [18] are present in the literature.

\subsection{Restriction of intramolecular motions and structural distortion}

The case of AIP originated from the restriction of intramolecular motions is conceptually the simplest to understand and has been invoked as responsible for the AIP phenomenon in most of organic systems [19-21]. Some of the examples shown below report applications of these complexes for mechano- or vapochromism, i.e. the change of color of the emission upon a mechanical stress (e.g. grinding or milling) or exposure to vapors (e.g. a solvent or a gas), respectively. In both cases, a change of the solid structure is responsible for the change in emission color and the process is reversible.

\subsection{1. $\mathrm{Cu}(\mathrm{I})$ complexes}

An intrinsic drawback of phosphorescent metal complexes is related to the high cost and low abundance of some metals, which limit their application in many fields. Indeed, the best candidates as phosphorescent materials contain rare metal ions of the second and third rows of the periodic table since spin-orbit coupling has a strong dependence on the atomic number, as previously mentioned. A notable exception is represented by $\mathrm{Cu}(\mathrm{I})$ complexes [22], which are low-cost alternatives [23-25] and can form a rich variety of multinuclear clusters.

$\mathrm{Cu}(\mathrm{I})$ is a $\mathrm{d}^{10}$ metal ion, so that its complexes do not exhibit lowenergy MC transitions. Due to the high tendency of $\mathrm{Cu}(\mathrm{I})$ to be oxidized to $\mathrm{Cu}(\mathrm{II})$, mononuclear $\mathrm{Cu}(\mathrm{I})$ complexes are characterized by lowest-energy MLCT electronic transitions, as long as empty $\pi$ orbitals are easily accessible in the ligands. The formal oxidation to $\mathrm{Cu}$ (II) in the excited state leads to a structural distortion that modifies the tetrahedral coordination towards a more flattened geometry. As a consequence, an exciplex can be formed by binding a coordinating solvent molecule as fifth ligand: the exciplex decays non-radiatively to the ground state and dissociates back to the initial state [26].Clearly, any factor which can limit the formation of the exciplex, i.e. increase of the structural rigidity and prevention of encounter with coordinating molecules, is able to increase the luminescence quantum yield, a situation that is particularly favorable for the AIP phenomenon.

$\mathrm{Cu}(\mathrm{I})$ complexes containing 1,10-phenanthroline (phen) derivatives and bis[2-(diphenylphosphino)-phenyl]ether displays high emission quantum yields in deaerated dichloromethane solution $(\Phi=0.16)$, compared to the prototype $\left[\mathrm{Cu}(\mathrm{phen})_{2}\right]^{+}$complex $\left(\Phi=10^{-3}-10^{-4}\right)$, from the long lived MLCT excited state ( $\tau=16 \mu \mathrm{s}$ ) [29]. The drawback of this family of complexes is that equilibrium between the homoleptic and the heteroleptic complexes is often observed in solution, as a result of the exceptionally high thermodynamic stability of the corresponding homoleptic 
(a)

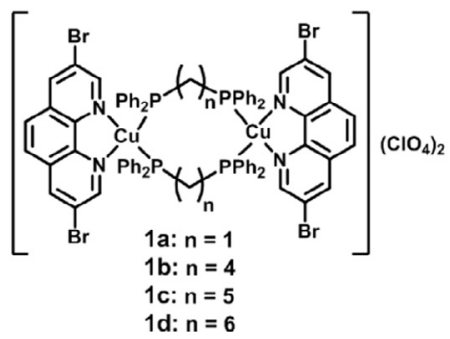

(b)

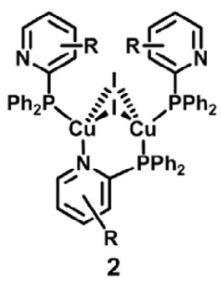

Fig. 2. Formula of (a) binuclear diimine-diphosphino $\mathrm{Cu}(\mathrm{I})$ complexes [27] and (b) a series of dinuclear $\mathrm{Cu}(\mathrm{I})$ complexes of general formula $\mathrm{Cu}_{2} \mathrm{I}_{2} \mathrm{~L}_{3}$ [28].

$\left[\mathrm{Cu}(\text { phen })_{2}\right]^{+}$complexes. To overcome this problem, binuclear complexes with diphosphine ligands bridging the two metal centers have been recently investigated [27]. The series of dinuclear phenanthroline-diphosphine complexes 1a-1d shown in Fig. 2a is stable towards dissociation for concentration above $2.5 \times 10^{-5} \mathrm{M}$ in air-equilibrated dichloromethane solution. All compounds are nearly non-emissive in solution and strongly phosphorescent in the solid state. This observation encouraged the authors to investigate their AIP behavior in a series of DCM/hexane solutions with different volumetric fractions. Emission colors spanning from green to yellow and red are obtained for the different complexes in their aggregated forms. In freshly-prepared solution with an hexane volumetric fraction superior to $90 \%$ compound 1a forms yellow-emissive amorphous aggregates, which turn into glittery green emissive crystals after 24 hours, followed by a 2-min sonication. The authors attributed the AIP effect to a restriction of molecular motions, with a clear dependence of the solid-state structure on the emission properties of the complexes.

Copper-halide clusters are another family of $\mathrm{Cu}(\mathrm{I})$ based multinuclear structures that display phosphorescence and have been largely investigated [30]. The series of dinuclear $\mathrm{Cu}_{2} \mathrm{I}_{2} \mathrm{~L}_{3}$ complexes ( 2 in Fig. $2 b, \mathrm{~L}=$ pyridyl ligand) displays remarkable AIP properties [28]. In deoxygenated dichloromethane solution, complexes with $\mathrm{R}=$ alkyl are weakly phosphorescent $(\Phi=2 \%)$ with an emission centered at $600 \mathrm{~nm}$. The emission quantum yield increases to 30$50 \%$ when the complexes are deposited as neat-film or dispersed in PMMA matrix, with a blue-shift of the emission maximum to about $550 \mathrm{~nm}$. A further shift to $500-520 \mathrm{~nm}$ occurs in solid powders, with emission quantum yields reaching values as high as 96\%. In accordance with the MLCT nature of the electronic transition, predicted also by theoretical calculations, the tuning of the energy of LUMO orbital centered on the ligand by introduction of substituents and expansion of the aromatic system yields powders with emission colors that span the full visible range, with high emission quantum yields. As previously discussed, for CT transitions, the singlet-triplet energy gap is very low, so that the upperlying $S_{1}$ state can be thermally populated from the lower-lying $T_{1}$ state, producing the so-called thermally activated delayed fluorescence (TADF). This phenomenon was first reported in the case of the prototypical $\mathrm{Cu}(\mathrm{I})$ bisphenanthroline complexes [31] and is now particularly important in view of their applications in OLED devices [32]: it allows all excitons generated by charge recombination $(25 \%$ $S_{1}, 75 \% T_{1}$ ) to emit from the $S_{1}$ state.

The tetranuclear $\mathrm{Cu}_{4} \mathrm{I}_{4}$ cubane cluster 3 (Fig. 3a) bearing triphenylphosphine ligands functionalized with cholesterol [33] can gelate from various solvents upon cooling hot solutions. The gel is green emissive and the emission can be used to probe the gelation kinetics of the system. The typical thermochromic properties of $\mathrm{Cu}_{4} \mathrm{I}_{4}$ clusters are displayed by the gel: a "low-energy" (LE) green $\left(\lambda_{\max }=535 \mathrm{~nm}\right)$ emission at $290 \mathrm{~K}$, due to a triplet cluster-centered transition (a combination of iodine to copper and metal-centered transitions, the term cluster centered emphasizes the fact that is essentially independent of the nature of the ligand L) is progressively substituted by an "high-energy" (HE) blue $\left(\lambda_{\max }=435 \mathrm{~nm}\right)$ emission upon cooling the gel to $110 \mathrm{~K}$, originating from a cluster-to-ligand CT state. This phenomenon is known to originate from a pronounced effect of the matrix rigidity on the nonradiative transitions that populate the triplet cluster-centered state.

\subsection{2. $\operatorname{Re}(I)$ complexes}

One of the first example of phosphorescence enhancement by rigidification is based on $\mathrm{Re}(\mathrm{I})$ tricarbonyl complexes with pyridine ligands, a widely investigated class of luminophores [34-38].

The alkoxy-bridged $\operatorname{Re}(\mathrm{I})$ molecular rectangle4 (Fig. 4a) is very weakly emissive $\left(\Phi=3.9 \times 10^{-4}\right)$ in deoxygenated $\mathrm{CH}_{3} \mathrm{CN}$. Upon addition of water, aggregates are formed with concomitant

(a)
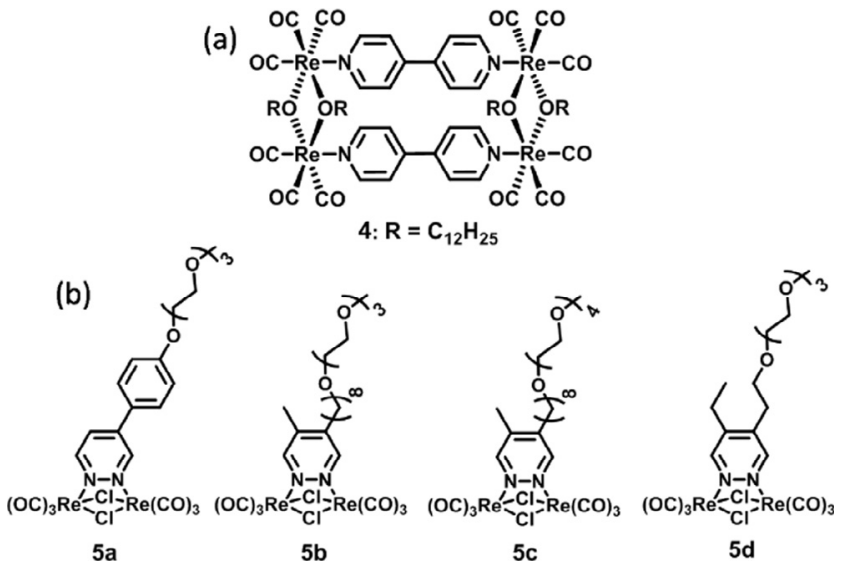

Fig. 4. Formula of (a)a tetranuclear Re(I) complex [39] and (b)a series of dinuclear $\operatorname{Re}(\mathrm{I})$ complexes [40].

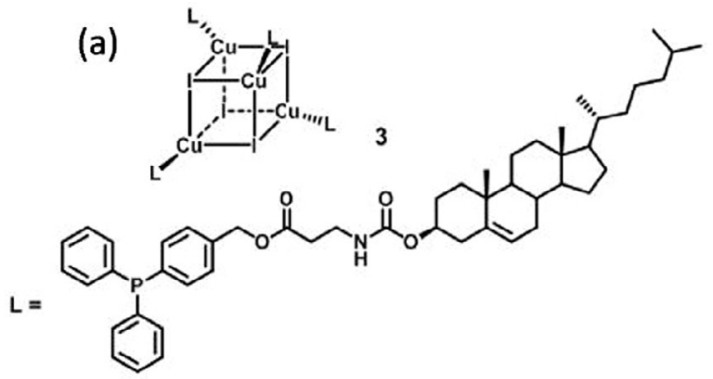

(b)

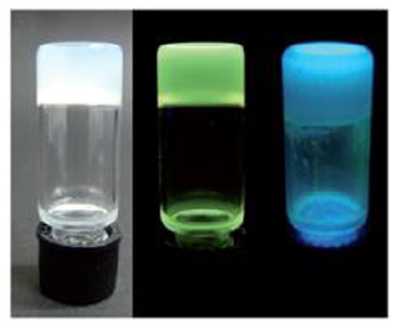

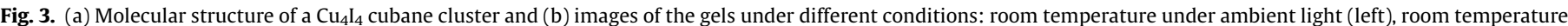

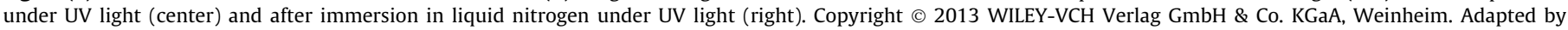
permission of John Wiley \& Sons, Inc. 
increase of the phosphorescence quantum yield $\left(\Phi=6.5 \times 10^{-3}\right.$ in deoxygenated $\mathrm{H}_{2} \mathrm{O} / \mathrm{CH}_{3} \mathrm{CN}$ 9:1(v/v)) and of the corresponding lifetime (from 11 to $212 \mathrm{~ns}$ ): these two parameters are dependent on the alkyl chain length and the AIP effect was attributed to the reduced mobility of the molecules in the aggregates.

Dinuclear $\operatorname{Re}(\mathrm{I})$ complexes functionalized with glycolic chains 5a-d (Fig. 4b) are amphiphilic molecules weakly phosphorescent in air-equilibrated dioxane solutions $(\Phi=0.02-0.04, \tau=0.44-$ $0.61 \mu \mathrm{s})[40]$. Upon addition of a large amount of water $\left(>8: 2 \mathrm{H}_{2^{-}}\right.$ O:dioxane $(\mathrm{v} / \mathrm{v})$ ), spherical aggregates are formed, as shown by DLS and STEM measurements, and a circa 10 times enhancement of both emission quantum yield and lifetime is observed. The luminescence enhancement is not only caused by reduced mobility in the aggregates, but also by shielding of the inner chromophoric units from dioxygen quenching, as demonstrated by the negligible increase in emission quantum yields and lifetimes upon deoxygenation.

The importance of the solid-state structure in tuning the emission properties of metal complexes is clearly demonstrated by the behavior of the $\operatorname{Re}(\mathrm{I})$ dinuclear complex reported in Fig. 5 [41]. Complex 6 displays a circa ten times increase in the quantum yield going from solution to crystalline state, which was attributed to a restriction of intramolecular motions of the $\mathrm{Me}_{3} \mathrm{Si}$ groups. Moreover, it can be crystallized in two different polymorphs with distinct photophysical properties: the monoclinic form emits green light $\left(\lambda_{\max }=534 \mathrm{~nm}\right)$ and the orthorhombic form yellow light $\left(\lambda_{\max }=570 \mathrm{~nm}\right.$, Fig. $5 \mathrm{~b}$ and $\left.\mathrm{c}\right)$. The origin of this behavior was ascribed by the authors to the differences in packing density and relative orientation of the molecular dipoles, that creates a different local environment for the emissive molecules. Structural distortion was ruled out by X-ray analysis. This further demonstrates the sensitivity of the AIP properties to the solidstate packing.

\subsubsection{Ir(III) complexes}

Due to their rich and tunable photophysical properties, cyclometalated $\operatorname{Ir}(\mathrm{III})$ complexes attracted an enormous interest [4245], in particular towards their application in optoelectronic devices [46], and consequently they are among the most investigated complexes in terms of their AIP properties.

One of the first report of $\operatorname{Ir}($ III) complexes showing aggregation phosphorescence enhancement was based on complexes 7a-c (Fig. 6), which have different phosphorescent properties depending on the ancillary ligand [47].

Complex 7a displays phosphorescence from the ${ }^{3}$ MLCT state both in solution and in the solid state, while $\mathbf{7 b}$ and $\mathbf{7 c}$ are orange-red emitting in the solid state and not luminescent in solution. For complexes7b and 7c dissolved in solution, the lowest triplet excited state is reported to be LC on the ancillary ligand. By a (a)<smiles></smiles><smiles>[Y]C(=O)C(=O)CCC(=O)O</smiles><smiles>O=C(/C=C(\O)c1ccccc1)c1ccccc1</smiles>

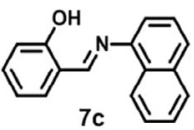

$7 \mathrm{~b}$

(c)
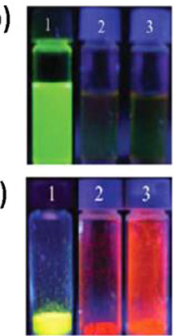

Fig. 6. (a) Formula of cyclometallated $\operatorname{Ir}(\mathrm{III})$ complexes containing differen ancillary ligands. Luminescence of 7a (1), 7b (2) and 7c (3) in $\mathrm{CH}_{2} \mathrm{Cl}_{2}$ solution (b) and solid state $(c)\left(\lambda_{\mathrm{ex}}=365 \mathrm{~nm}\right)$. Adapted from Ref. [47] with permission from The Royal Society of Chemistry.

combined experimental and theoretical approach based on X-ray crystallography and DFT calculations, $\pi-\pi$ interactions between adjacent phenylpyridyl (ppy) ligands were suggested to be responsible of the formation of a new ${ }^{3}$ MLLCT state at lower energies, from which emission takes place. Similar behavior was observed for $\operatorname{Ir}(\mathrm{III})$ complexes featuring $\beta$-diketonate ligands and the authors interpreted the results as in the case of complexes $\mathbf{7 b - c}$ [48]. These reports fostered a debate: restriction of intramolecular rotation around the $\mathrm{N}$-aryl bond was proposed as an alternative explanation [49] since phosphorescence of similar complexes was observed not only in the solid state, but also when the complex was embedded in a polymer matrix at very low concentration. On the other hand, the authors of the first paper reported that even complexes with iminic ligands in which the phenyl ring could not rotate due to covalent bonding exhibited AIP properties, thus rejecting the thesis of restriction of intermolecular motion [50]. A detailed photophysical, computational and crystallographic investigation of a series of similar complexes $\left[\operatorname{Ir}\left(\mathrm{C}^{\wedge} \mathrm{N}\right)_{2}\left(\mathrm{~N}^{\wedge} \mathrm{O}\right)\right]$ featuring two phenylpyridine ligands and an ancillary ligand coordinated by $\mathrm{N}$ and $\mathrm{O}$ atoms [51] showed that neither the first hypothesis of ligand $\pi-\pi$ interactions, nor the second hypothesis of restriction of $\mathrm{N}$-aryl bond rotation can explain all the experimental data. The authors suggested that the main cause of AIP is a distortion of the bonding of the six-membered chelate ring of the ancillary ligand to the metal atom on the basis of a combined experimental and computational study. This example illustrates the complexity of the AIP phenomenon and the possible interplay of different mechanisms.

Neutral cyclometalated $\operatorname{Ir}($ III) complexes 8a-b (Fig. 7),in which the ancillary ligand is functionalized with anionic surfactants, form spherical bilayer structures when dissolved in $\mathrm{mM}$ concentration in aqueous solution [52]: the anionic chains (blue parts in Fig. 7b) align towards the aqueous phase and the hydrophobic complexes are localized in the apolar phase (green spheres in Fig. 7b). Interestingly, the emission properties change from a structured green (a)

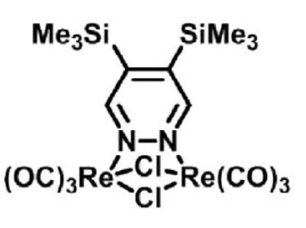

6 (b)

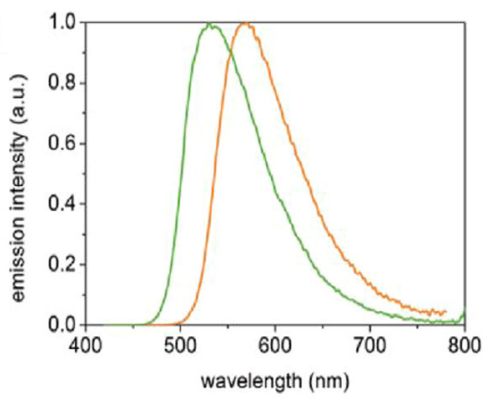

(c)

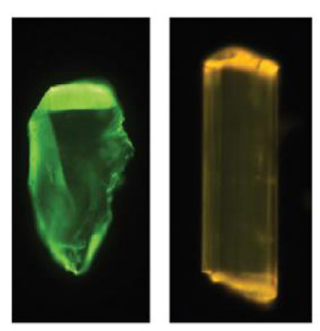

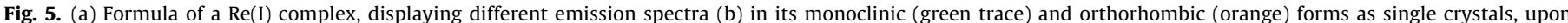

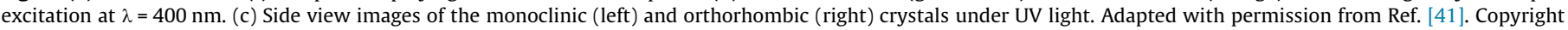
2010 American Chemical Society. 

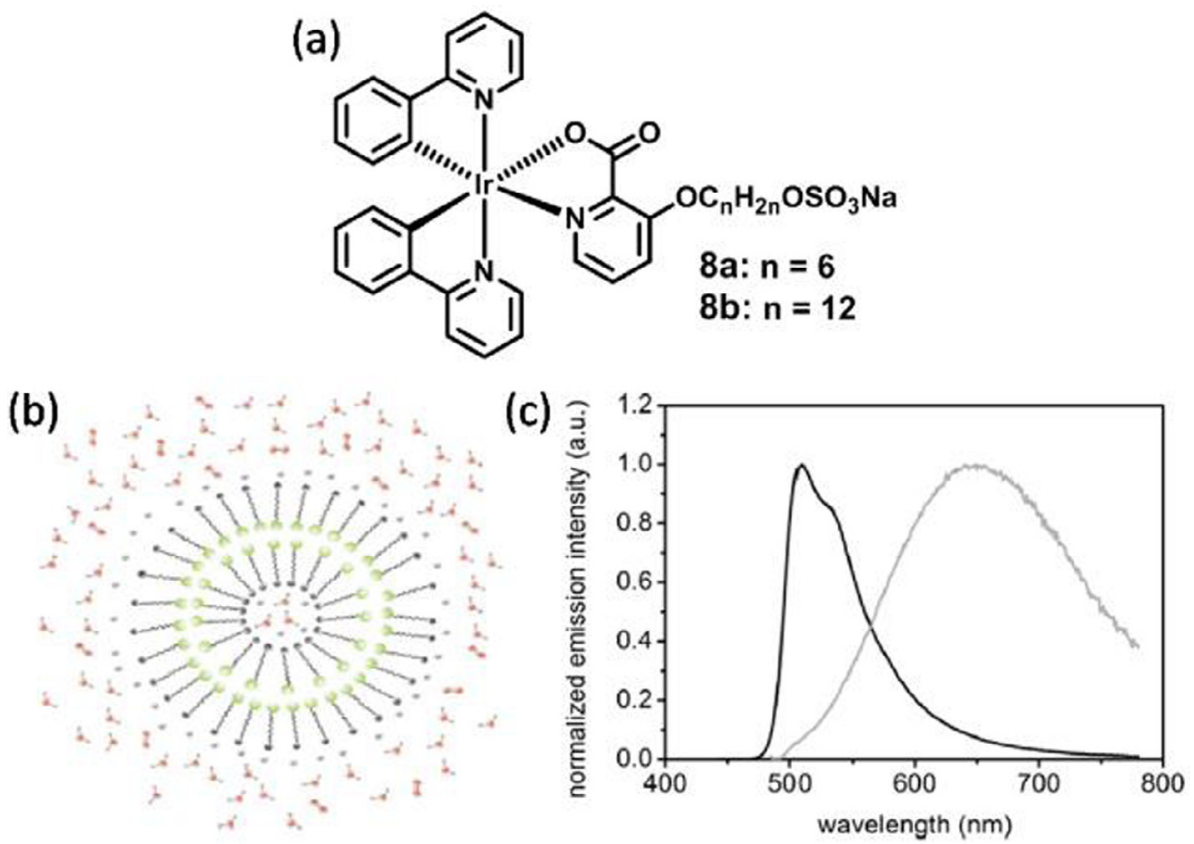

Fig. 7. (a) Formula of $\operatorname{Ir}(\mathrm{III})$ complexes bearing an ancillary ligand functionalized with anionic surfactants. (b) A schematic picture of the self-assembled structure of the amphiphilic complexes in water. (c) Normalized emission spectra of complex $8 \mathrm{a} 1.8 \times 10^{-3} \mathrm{M}$ (black trace) and $1.0 \times 10^{-5} \mathrm{M}$ (gray trace) in air-equilibrated $\mathrm{H}_{2} \mathrm{O}$. Adapted from Ref. [52] with permission from The Royal Society of Chemistry.

(a)

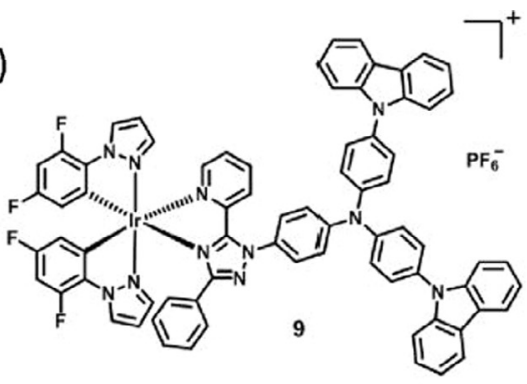

(b)

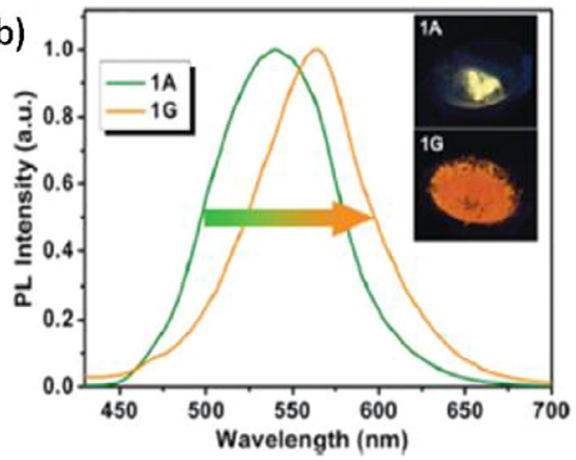

(c)

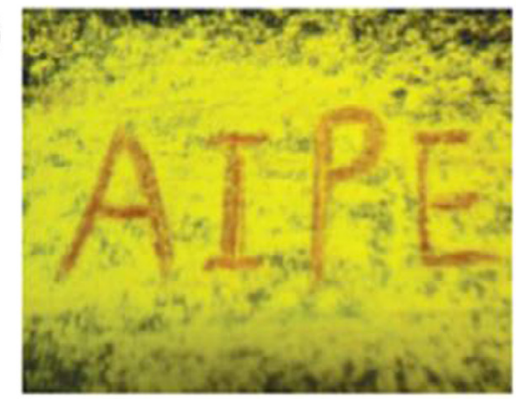

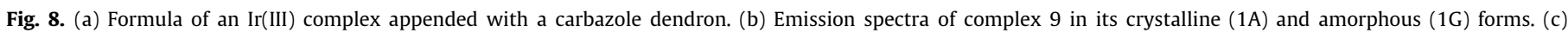

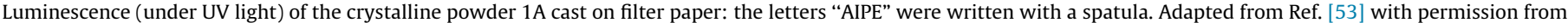
The Royal Society of Chemistry.

emission for the isolated complexes dissolved in water at $1 \times 10^{-5} \mathrm{M}$ concentration (black line in Fig. 7c) to a broad orange-red emission for the aggregated complexes in the bilayer structure (concentration: $1 \times 10^{-3} \mathrm{M}$, grey line in Fig. $7 \mathrm{c}$ ).

AIP behavior was reported for a series of cationic cyclometalated Ir(III) complexes functionalized with groups possessing high rotational (such as carbazole dendrons and phenyl rings [53,54]) or vibrational mobility (alkyl chains [55]). For example, complex $\mathbf{9}$ is very weakly emissive in organic solvents and brightly phosphores- cent in the solid state or upon aggregation in $\mathrm{CH}_{3} \mathrm{CN} / \mathrm{H}_{2} \mathrm{O}$ mixtures. Interestingly, the compound exhibits a yellow emission (with a spectral profile similar to the isolated molecule in solution) in its crystalline state and an orange emission (with a spectral profile similar to the aggregates in solution) in its amorphous state, obtained upon grinding (see Fig. 8). This mechanochromic effect highlights the importance of the solid state morphology on the luminescence properties and the utility of this phenomenon to elucidate the structure of aggregates in solution by comparison with 
solid state, which can be easily investigated with standard structural characterization techniques such as X-ray crystallography.

Cationic non-cyclometalated $\operatorname{Ir}(\mathrm{III})$ complex 10 (Fig. 9) [56] is very weakly emissive in solvents such as dichloromethane or ethyl acetate, with an identical spectral shape irrespectively of the nature of the counterions. Upon aggregation in ethyl acetate/hexane mixtures and in the crystalline solid state, complexes $\mathbf{1 0}\left(\mathrm{BF}_{4}\right)$ and $\mathbf{1 0}\left(\mathrm{PF}_{6}\right)$ exhibit a bluish and more vibrationally structured emission compared to the greenish emission of $10(\mathrm{Cl})$ and $10(\mathrm{~N}$ $(\mathrm{CN})_{2}$ ) (Fig. 9b). Furthermore, the green emissive crystalline $\mathbf{1 0}$ (Cl) can be turned into an amorphous yellow emissive form upon exposure to $\mathrm{CH}_{2} \mathrm{Cl}_{2}$ or $\mathrm{CHCl}_{3}$ vapors (vapochromism), elucidating the importance of the structure in controlling the photophysical properties. A computational investigation evidenced that the phosphorescent MLCT excited state has a considerably distorted geometry with respect to the ground state (with a decrease of the P-Ir-P angle of about $20^{\circ}$ ). The reduced possibility of rearrangement the molecular geometry in the closely packed structure of the solid state is the most plausible origin of the phosphorescence enhancement and it is supported by the crystallographic study evidencing interactions between the triphenylphosphine ligands on neighboring molecules.

\subsubsection{Pt(II) complexes}

$\mathrm{Pt}(\mathrm{II})$ complexes [57] usually display square planar geometry, so that the $\mathrm{d}_{x 2-y 2}$ orbital is strongly antibonding. For Pt(II) complexes with simple ligands, like halogens, amines, the lowest energy electronic transition is metal-centered, so that the $\mathrm{d}_{x 2-y 2}$ orbital is populated through absorption of light: the molecule thus undergoes a significant distortion upon formation of the excited state and Pt ligand bond lengths increase. This means that the lowest excited state is strongly distorted compared to the ground-state, so that the rate constant of non-radiative decay is large, while the radiative decay rate constant is typically small for Laporte-forbidden d-d transitions. Thus, Pt(II) complexes with low-lying MC states are generally non-emissive. The introduction of ligands containing $\pi$ orbitals gives rise to novel LC and MLCT states. The relative energies of MLCT, LC and MC states (which can be thermally accessible from lower-lying states) controls the photophysics of the complex [5862]. Population of ${ }^{3}$ MLCT states often implies a structural distortion of the complex geometry. In the solid state or at low temperatures, distortion of molecules is inhibited to some extent, and this contributes to the AIP effect, as reported in the examples below.

Restricted structural distortion, as well as reduction of oxygen quenching, are the main cause of phosphorescence enhancement for the series of cyclometalated Pt(II) complexes with iminic ancillary ligands 11a-f (Fig. 10a) [63]. They are non-emissive in solution, but strongly emissive in the solid state and upon aggregation in $\mathrm{THF} / \mathrm{H}_{2} \mathrm{O}$ mixtures. TDDFT calculations suggested that a strong structural distortion occurs upon population of the $\mathrm{T}_{1}$ excited state in solution, leading to an efficient non-radiative deactivation, as expected also from the high mobility of the phenyl and alkyl substituents on the iminic nitrogen. In the aggregated state, the restriction of the structural distortion leads to a change in the nature of the excited state, with the participation of orbitals on the cyclometalated ligand (Fig. 10b).

The cis-Pt(II) complex 12 (Fig. 11a) is not luminescent in deaerated solution of organic solvents, and strongly luminescent in rigid matrix at $77 \mathrm{~K}$ [64]. Moreover, complex 12 is vapoluminescent: the crystals obtained from toluene solution are very weakly luminescent and exposure to $\mathrm{CH}_{3} \mathrm{OH}$ vapors switches on a luminescence visible to the naked eye under UV excitation (Fig. 11b). This vapoluminescence effect cannot be attributed to a disruption of intermolecular Pt...Pt interactions since the single crystal X-ray diffraction analysis of complex cis-12 crystallized from toluene, cis-12. $\mathrm{C}_{6} \mathrm{H}_{5} \mathrm{CH}_{3}$, revealed a molecular structure almost identical to that found in cis-12.2 $\mathrm{CH}_{3} \mathrm{OH} \cdot \mathrm{CH}_{3} \mathrm{CN}$, with a minimum Pt...Pt intermolecular distance of $5.9267(2) \AA$ and $8.9268(2) \AA$, respectively. In the solid state structure of cis-12.2 $\mathrm{CH}_{3} \mathrm{OH} \cdot \mathrm{CH}_{3} \mathrm{CN}$, a $\mathrm{CH}_{3}$ $\mathrm{OH}$ molecule forms a hydrogen bond with each exo-cyclic nitrogen atoms of the complex. The more rigid structure, which prevents strong distortion also in the excited state geometry, explains the increase of emission quantum yield, because deactivation by non-radiative decays is slowed down.

\subsection{Metallophilic interactions}

The most investigated mechanism of AIP in planar $\mathrm{d}^{8}$ (e.g. Pt(II) and $\mathrm{Pd}(\mathrm{II}))$ and $\mathrm{d}^{10}($ e.g. $\mathrm{Au}(\mathrm{I}), \mathrm{Ag}(\mathrm{I}), \mathrm{Cu}(\mathrm{I}))$ metal complexes is based on metallophilic interactions $[13,65]$.

\subsubsection{Pt(II) complexes}

The square planar geometry favors interactions of Pt(II) complexes with other identical molecules or with molecules of different type, such as the solvent. The so-called "metallophilic interaction" leads to the orbital diagram shown in Fig. 12. The $\mathrm{d}_{z 2}$ orbital, perpendicular to the plane of the molecule, can interact with the $d_{z 2}$ orbitals of adjacent molecules when the intermolecular Pt-Pt distance is of the order 3.0-3.5 A to form weakly bonding and antibonding $\mathrm{d}_{\sigma}$ and $\mathrm{d}_{\sigma}{ }^{*}$ molecular orbitals (Fig. 12). As a result of such interactions, the highest occupied metal-based molecular orbital is raised in energy compared to that of the isolated molecules, so that the corresponding electronic transitions are shifted to lower energies. If these interactions are quite strong, a switch of the nature of the lowest-energy excited state can occur; for example, in Fig. 12, from LC $\left(\pi-\pi^{*}\right)$ in the isolated monomers to (a)

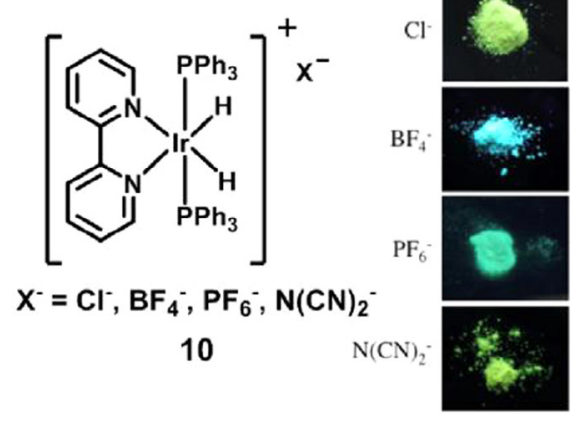

(c)

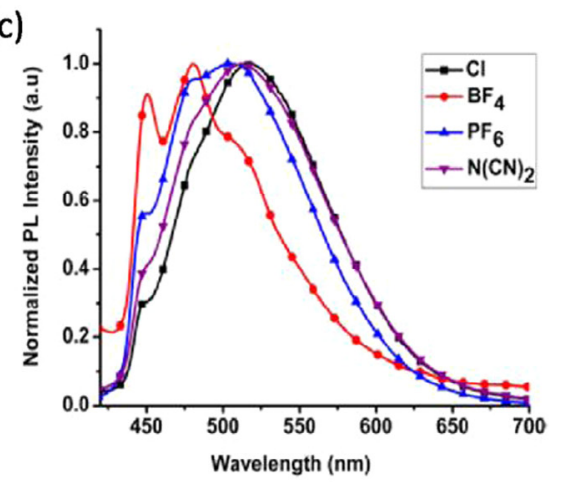

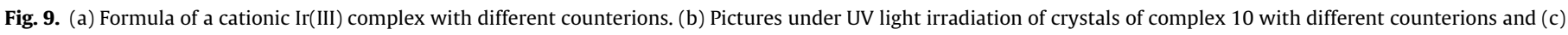
corresponding emission spectra $\left(\lambda_{\text {exc }}=385 \mathrm{~nm}\right)$. Adapted with permission from Ref. [56]. Copyright 2016 American Chemical Society. 
(b)

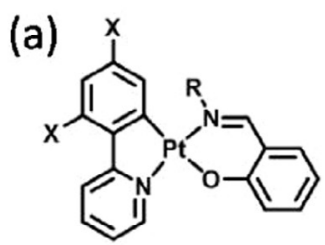

11a: $X=H, R=P h$

11b: $X=H, R=$ Naph

11c: $X=H, R=n-P r$

11d: $X=F, R=P h$

11e: $X=F, R=$ Naph

11f: $X=F, R=n-P r$

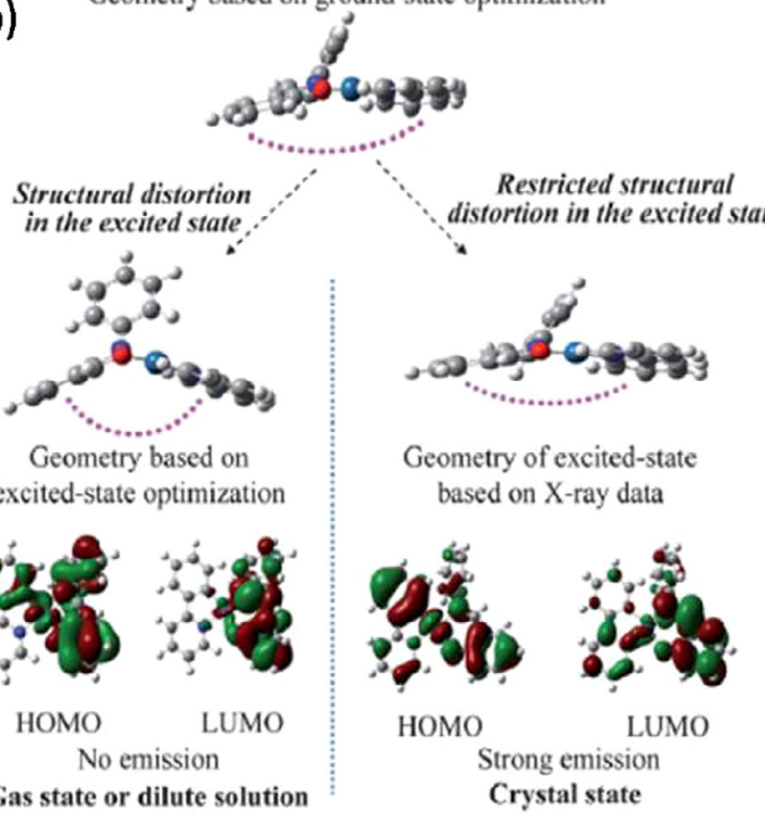

Fig. 10. (a) Formula of a cyclometalated Pt(II) complex. (b) Calculated geometries and molecular orbitals of complex 11a in different states. Adapted from Ref. [63] with permission from The Royal Society of Chemistry.

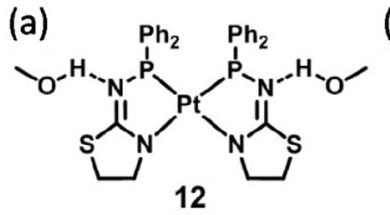

(b)

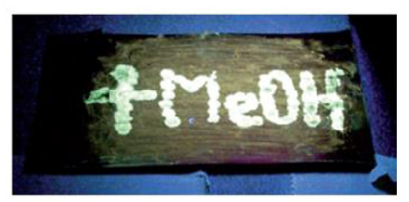

Fig. 11. (a) Formula of a Pt(II) complex displaying vapoluminescence. (b) Photograph of an aluminum foil covered by a thin layer of the dry complex cis-12 under UV light. The emission is restricted to areas in which the layer was treated with drops of $\mathrm{CH}_{3} \mathrm{OH}$ [64]. Copyright $\odot 2007$ WILEY-VCH Verlag GmbH \& Co. KGaA, Weinheim. Adapted by permission of John Wiley \& Sons, Inc.

MMLCT (metal-metal to ligand charge transfer, $\mathrm{d} \sigma^{*}-\pi^{*}$ ) in the presence of such interactions. The energy of this electronic transition can be modulated by tuning the metal distances: shorter M-M distances correspond to lower energy transitions and vice versa. Moreover, for complexes with planar, conjugated aromatic ligands, $\pi-\pi$ interactions between the ligands of adjacent molecules are also possible, as schematically presented in Fig. 12.
Such metallophilic interactions in $\mathrm{Pt}(\mathrm{II})$ complexes are known since the '70s [66,67], but they have recently attracted an increasing attention in the field of luminescent materials [68].

The very simple complex $[\mathrm{Pt}(\mathrm{tpy}) \mathrm{Cl}]^{+}$features a tridentate tepyridine ligand that imposes a planar geometry. However, the bite angle of terpyridine is not ideal for Pt(II) ions: the ligand field is reduced, and the d-d excited states that promote thermally activated non-radiative decay, as discussed in Section 3.1.4, are lowered in energy. Therefore, irrespective of the counterion, the [Pt (tpy)Cl $]^{+}$cation is essentially non-emissive in fluid solution at room-temperature, while in dilute $(<10 \mu \mathrm{M})$ glassy solution at $77 \mathrm{~K}$, it displays a structured LC phosphorescence with maximum at $465 \mathrm{~nm}$. At higher concentrations in frozen glasses, a broad, weakly structured band centered at $600 \mathrm{~nm}$, and an unstructured band at $720 \mathrm{~nm}$ are observed. These have been assigned to aggregates, involving $\pi-\pi$ and metal-metal interactions $\left({ }^{3} \mathrm{MMLCT}\right.$ excited state), respectively [58]. Furthermore, the complex is emissive also in the solid state: the energy of the electronic transition is strongly influenced by the identity of the counteranion, as exem- (a)

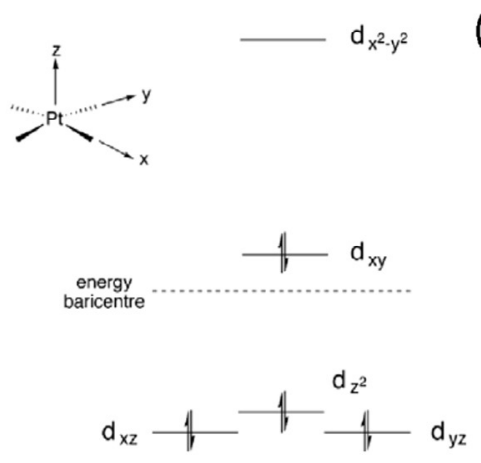

(b)

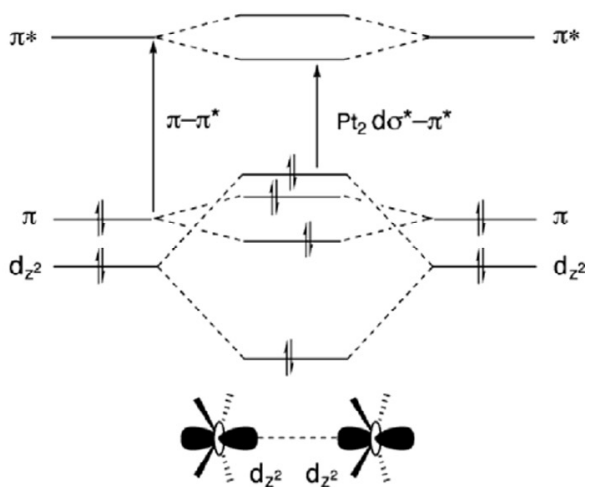

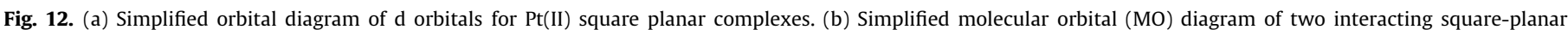

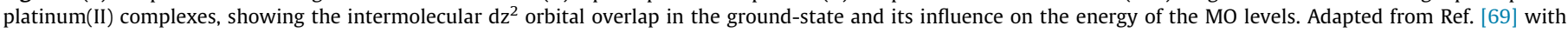
permission. Copyright $\odot$ 2007, Springer-Verlag Berlin Heidelberg. 
plified by the dramatic difference between the $\mathrm{SbF}_{6}^{-}$and $\mathrm{CF}_{3} \mathrm{SO}_{3}^{-}$ salts [70].

Metallophilic interactions were reported also for $\mathrm{Pt}(\mathrm{II})$ complexes containing the tridentate analogue 2,6-bis(benzimidazol-2 -yl)pyridine both in concentrated solutions [61] and in the solid state [72]. In particular, the series of amphiphilic complexes 13ac (Fig. 13a) exhibits a peculiar aggregation behavior with a rich and diversified photophysics [71]. The potassium salt of complex 13a can be isolated in two different solid state forms: a yellow powder, which shows a structured green emission (orange line in Fig. 13d) similar to that of the isolated complex in solution, and a blue powder, in which a new band is observed both in absorption (with maximum around $600 \mathrm{~nm}$, blue line in Fig. 13b) and in emission (with maximum around $700 \mathrm{~nm}$, blue line in Fig. 13b). The behavior exhibited by the blue powder is consistent with metallophilic interactions. Similar photophysical properties were observed in water solution due to the formation of aggregates, which can be reversibly disassembled through temperature increase, as demonstrated by a progressive disappearance and blue-shift of the MMLCT absorption and emission bands, as a consequence of the elongation of the average Pt-Pt distances. The same behavior was observed upon addition of acetone to the aqueous solution containing the aggregates: the emission intensity reaches a minimum for acetone fractions between 50 and $70 \%$. Increasing the fraction of acetone up to $100 \%$ unexpectedly gave rise to a strong recovery of the emission intensity, with spectral features indicating a closer packing of the emissive complexes, which was attributed to the formation of elongated fibers, as observed by TEM/SEM microscopy. The strong color change of the solution (Fig. 13b), which passes from red in pure water to blue in pure acetone, is a clear demonstration of the sensitivity of metallophilic interactions to different aggregation states based only on the average $\mathrm{M}-\mathrm{M}$ distance.

This remarkable property has been exploited for the luminescence-based detection and imaging of metastable kinetically trapped aggregation morphologies [73].

The amphiphilic $\mathrm{Pt}$ (II) complex 14 (Fig. 14a) is weakly emissive in dioxane solution $(\Phi=0.01, \tau=2.6 \mathrm{~ns})$, but upon flash injection in water forms brightly orange emissive spherical aggregates
( $\Phi=0.84, \tau=646 \mathrm{~ns}$ ), as a result of strong metallophilic interactions. This form is metastable and evolves over time into thermodynamically stable fibers. The fibers have a blue emission identical in shape and energy to that exhibited by the isolated complex in solution (monomer), but a higher quantum yield ( $\Phi=0.20, \tau=1.08 \mu \mathrm{s}$ ), due to the restriction of molecular motion and reduced quenching by dioxygen. A third intermediate structure was observed in the transformation process and it has a green emission due to weaker Pt-Pt interactions with respect to the orange emissive one. Remarkably, AIP was exploited to determine the nucleation and elongation kinetics for the formation of the blue emissive fibers and to follow the orange to blue transformation process by phosphorescence microscopy, that allowed to visualize directly the relationship between the emission color and the structure of the aggregates, further confirming the utility of the AIP phenomenon in the investigation of complex aggregation behaviors.

$\mathrm{Pt}(\mathrm{II})$ complexes possessing chiral ligands display aggregation induced circularly polarized luminescence (AICPL) [74]. The chiral monomers 15a-b (Fig. 15) are weakly emissive in $\mathrm{CHCl}_{3}$ or toluene in their monomeric forms $(\Phi \approx 0.025)$ and show a strong solventdependent aggregation behavior. Upon increasing the concentration of a $\mathrm{CHCl}_{3}$ solution, a non-helical assembly featuring Pt-Pt interactions is formed. A new ${ }^{3} \mathrm{MMLCT}$ emission band is visible, but the overall emission quantum yield decrease upon aggregation due to competing quenching phenomena. On the contrary, in toluene helical structures are formed, featuring an enhancement of the emission quantum yield and an elongation of the phosphorescence lifetime attributed to the restriction of molecular motion, since no M-M interactions are observed. Interestingly, these structures are able to emit circularly polarized light with high dissymmetry factors due to their chiral assembly, thus showing the importance of AIP in the field of CPL emission. By slow evaporation of the solvents, two different solid forms are obtained that retain the photophysical properties of the corresponding aggregates. Also in this case, it is possible to follow both the formation of the helical aggregates in toluene and the slow interconversion of the kinetically trapped non-helical aggregates to the thermodynamically stable CPL emissive helices in the same solvent. (a)

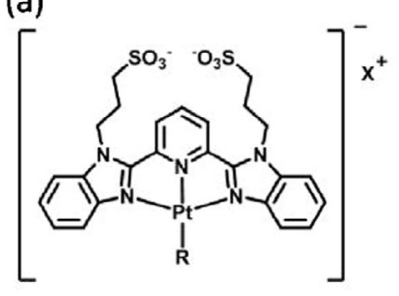

(b)

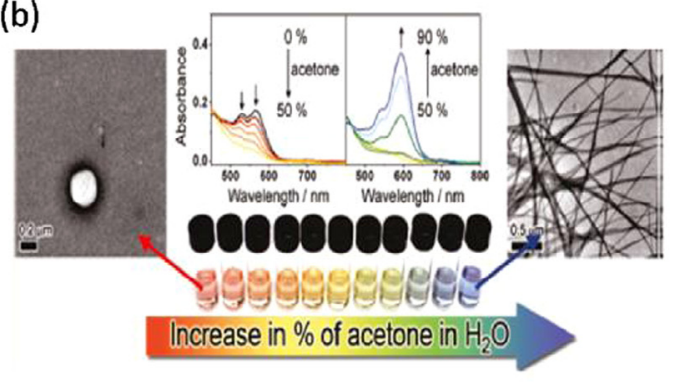

(c)

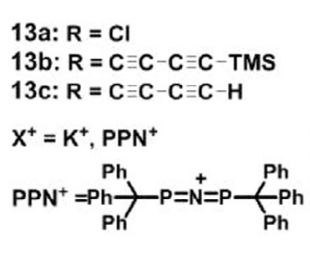

(d)
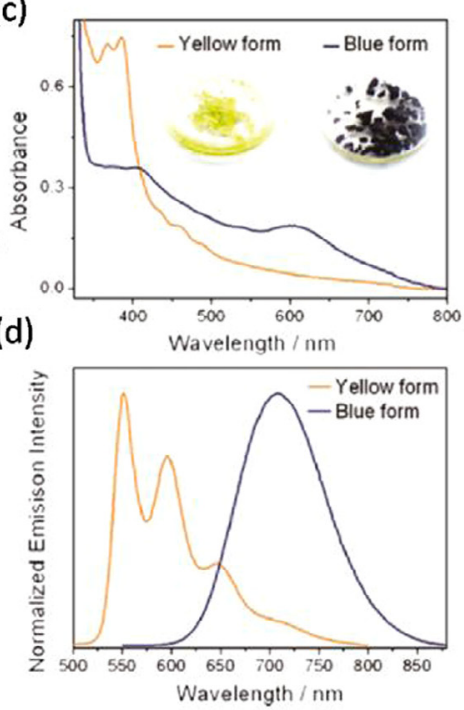

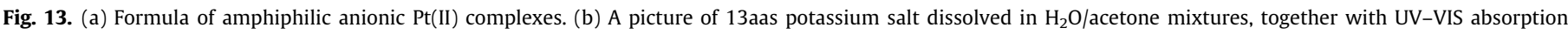

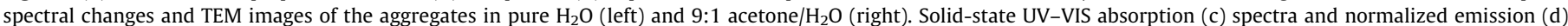
spectra of $13 \mathrm{a} \cdot \mathrm{K}^{+}$in yellow and blue forms at room temperature. Adapted with permission from Ref. [71]. Copyright 2011 American Chemical Society. 
(a)

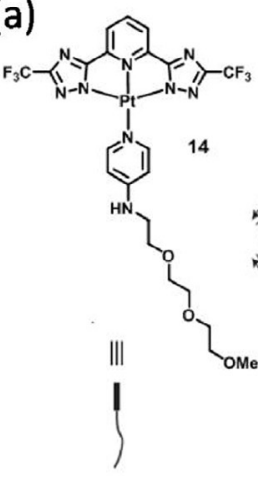

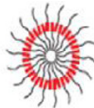
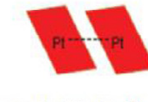

Oth-patrway<smiles>[AlH2]</smiles>

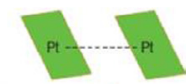

Kinetically trapped metastable state (B)

Ott-pathwa/

$\uparrow$ hv

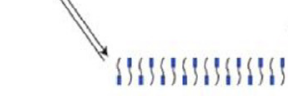

(b)
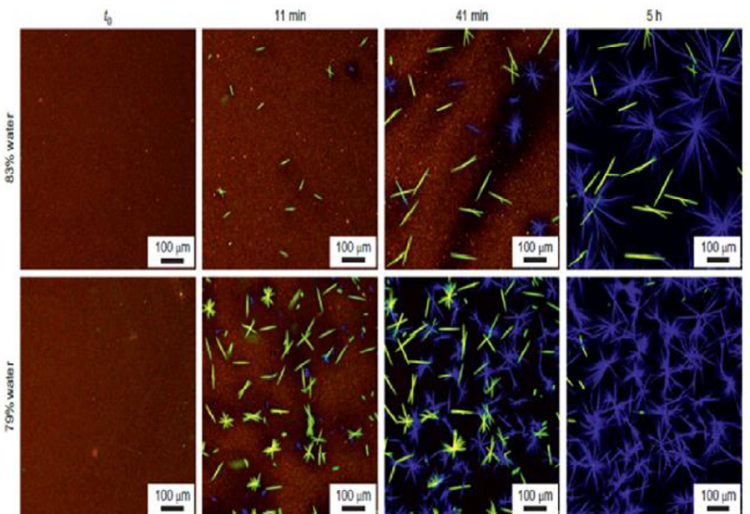

Fig. 14. (a) Schematic representation of the supramolecular structures formed by an amphiphilic Pt(II) complex: the colors correspond to the emission color of the aggregates. (b) Fluorescence microscopy $\left(\lambda_{\text {exc }}=405 \mathrm{~nm}\right.$ ) snapshots of the time-dependent evolution of assembly A (red) into B (green) and C (blue). The upper and lower rows were taken at 83 and 79\% water, respectively. Figures adapted with permission from Macmillan Publishers Ltd: Nature Chemistry. Ref. [73], copyright 2015.

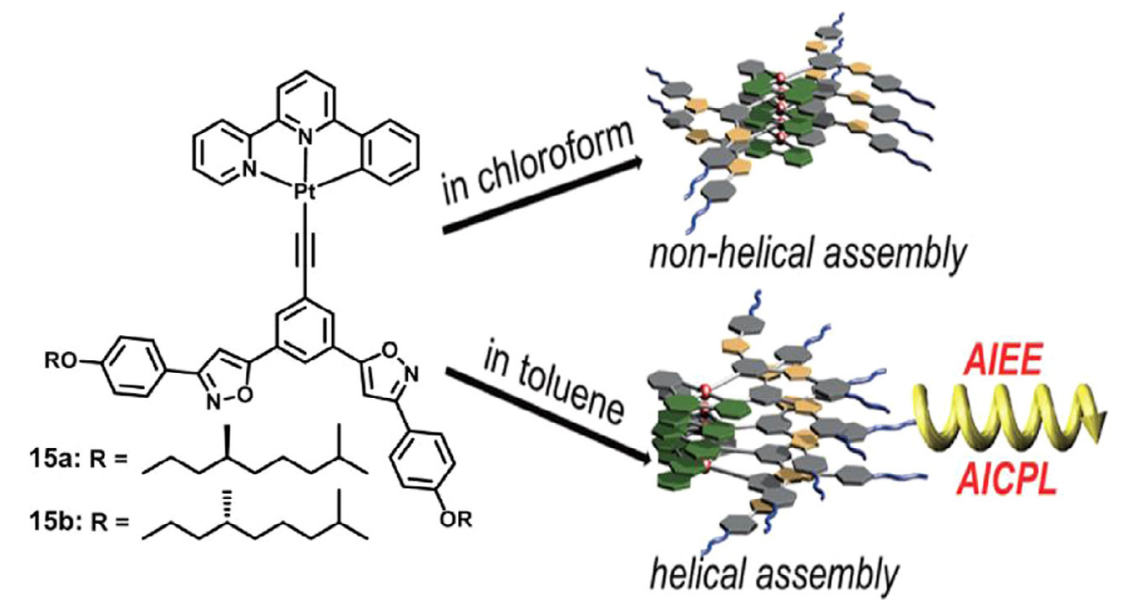

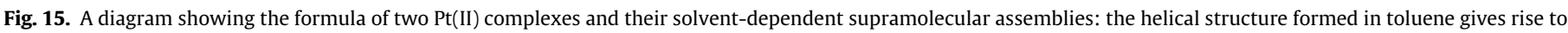
aggregation induced circularly polarized luminescence (AICPL). Adapted from Ref. [74] with permission from The Royal Society of Chemistry.

(a)

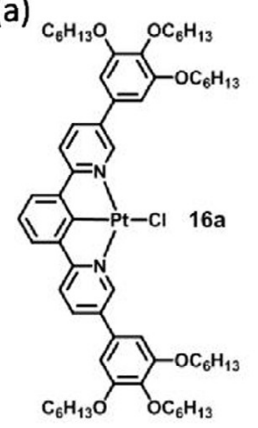

(b)

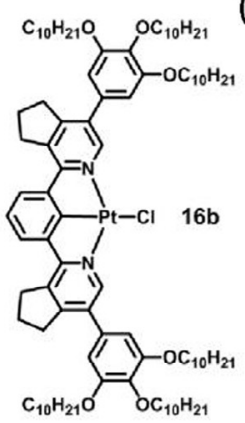

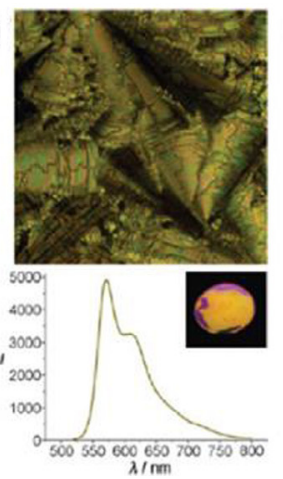

(c)
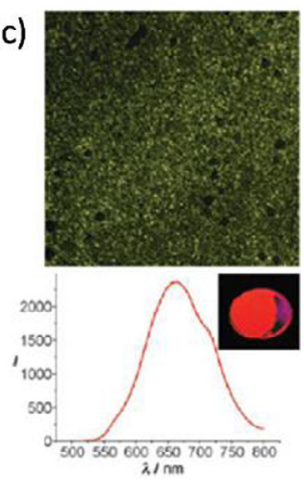

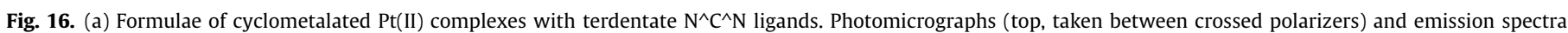

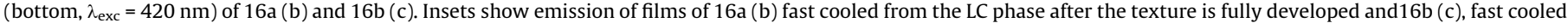
direct from the isotropic phase. Copyright $\odot 2008$ WILEY-VCH Verlag GmbH \& Co. KGaA, Weinheim. Adapted from Ref. [58] by permission of John Wiley \& Sons, Inc.

Cyclometalated Pt(II) complexes with terdentate N,C,N ligands (Fig. 16a) possessing long alkyl chains were used to form luminescent liquid crystals [75], exploiting the planar geometry of the metal coordination. Compound 16a is weakly luminescent in solution, in accordance with the LC character of the transition, while in the liquid crystalline phase has a phosphorescence behavior that depends on the thermal history of the sample. When an isotropic melt is slowly cooled to $170{ }^{\circ} \mathrm{C}$ and then rapidly cooled to room temperature, large anisotropic domains are formed, which present an emission spectrum similar to the monomeric one. On the other 
hand, when the rapid cooling occurs directly from the melt, small anisotropic domains are obtained, featuring an unstructured emission at longer wavelengths typical of metallophilic interactions. The same emission is observed upon formation of a thin film of 16b by spin-coating, but the color can be tuned by thermal annealing $\left(110^{\circ} \mathrm{C}\right)$ and cooling cycles, which increase the amount of monomer. Mechanical stimulation (scratching) induces the opposite phenomenon of aggregation, thus assessing the potential of the material in a phosphorescent writable device that can be erased thermally.

\subsection{2. $A u(I)$ complexes}

$\mathrm{Au}(\mathrm{I})$ complexes [76-80] usually display a linear geometry; metal-metal, named aurophilic, interactions can arise in the solid state or in polynuclear $\mathrm{Au}(\mathrm{I})$ complexes. For example, mononuclear gold complexes featuring non-sterically demanding ligands undergo intermolecular aggregation via short sub-van der Waals gold-gold contacts of $c a$. 3.0 ̊. The related bond energy is of the order of $5-10 \mathrm{kcal} \mathrm{mol}^{-1}$ and it is comparable to that of standard hydrogen bonds $[81,82]$. In the same way, intramolecular $\mathrm{Au}-\mathrm{Au}$ interactions yield significant stabilization to multinuclear gold complexes. Moreover, relativistic effects [83] related to the movement of high-speed electrons in close proximity of a heavy atomic nucleus, particularly important in the case of gold, cause an increase in the effective nuclear charge. This results in a lower energy difference between the filled $5 d$ orbitals $\left(\mathrm{Au}(\mathrm{I})\right.$ is a $\mathrm{d}^{10}$ metal ion) and the empty $6 \mathrm{~s} / 6 \mathrm{p}$ orbitals and leads to a more extended orbital overlap, favoring metal-metal interactions.
These aurophilic interactions are responsible of AIP effects in the examples reported below.

The dinuclear complexes 17a-c [84] are very weakly emissive in polar organic solvents and brightly yellow-green emissive upon addition of water, due to the formation of aggregates featuring $\mathrm{Au}-\mathrm{Au}$ interactions. Interestingly, the phosphorescence is very weak in the solid crystalline state and strongly enhanced upon transition to an amorphous state through grinding (mechanochromism, Fig. 17B a-f). The emission can be reversibly switched off by thermal annealing (thermochromism) or exposure to solvent vapors (vapochromism, Fig. 17C).

The trinuclear pyrazolate $\mathrm{Au}(\mathrm{I})$ complex 18 [85] (Fig. 18A) has a highly planar structure and is able to gelate by self-assembling into columnar stacks. While the complex is non-emissive in solution, the sol-gel transition is accompanied by a strong AIP effect resulting in a bright red emissive gel. The color of the emitted light could be modulated by addition of $\mathrm{Ag}^{+}$ions, that intercalate into the columnar stacks due to heteroatomic metallophilic interactions and turn the system into green emissive in solution and blue emissive in the gel state. Remarkably, the effect can be reversed by addition of $\mathrm{Cl}^{-}$ions to sequester $\mathrm{Ag}^{+}$ions, thus realizing a reversible RGB color-tunable system based on AIP.

As a proof of the analogies among coinage metals regarding metallophilic interactions, trinuclear pyrazolate complexes of $\mathrm{Cu}$ (I), $\operatorname{Ag}(\mathrm{I})$ and $\operatorname{Au}(\mathrm{I})$ functionalized with dendritic units can all self-assemble into phosphorescent columnar stacks [86] and the $\mathrm{Cu}(\mathrm{I})$ species were applied in a rewritable thermosensitive phosphorescent paper [87]: it can be written and erased through ther-
(A)

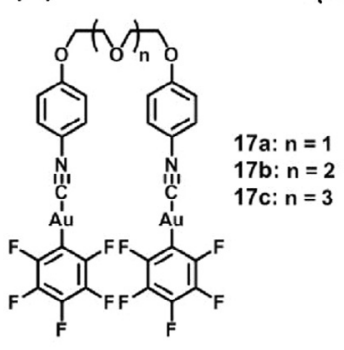

(B)

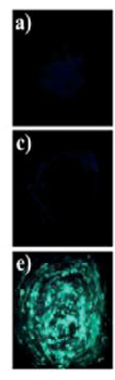

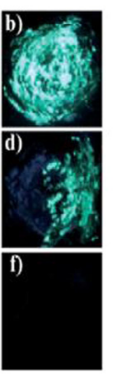

(C)

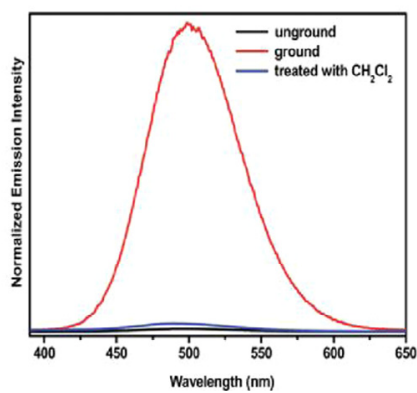

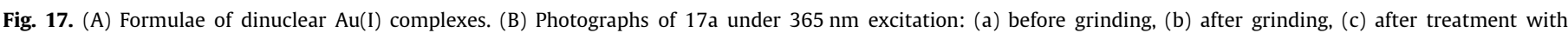

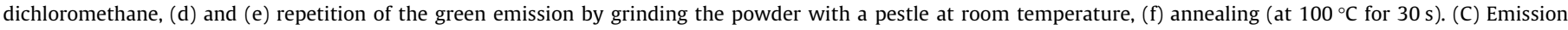

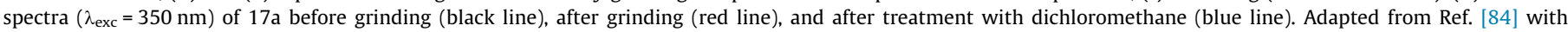
permission from The Royal Society of Chemistry.

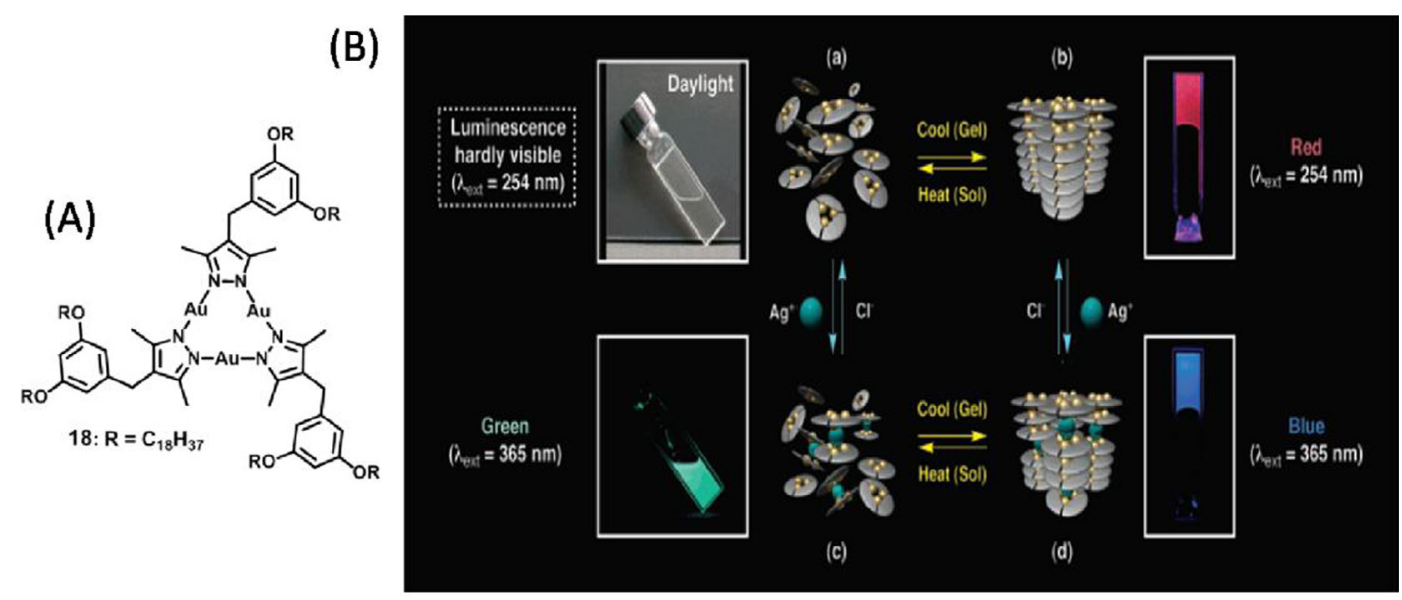

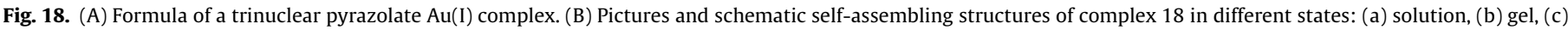
solution containing AgOTf (0.01 equiv) and (d) gel containing AgOTf (0.01 equiv). Adapted with permission from Ref. [85]. Copyright 2005 American Chemical Society. 
(a)

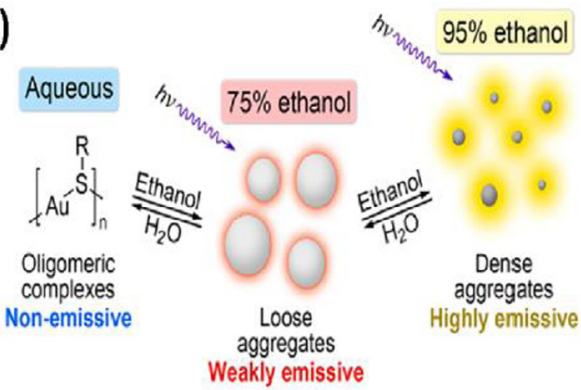

(b)

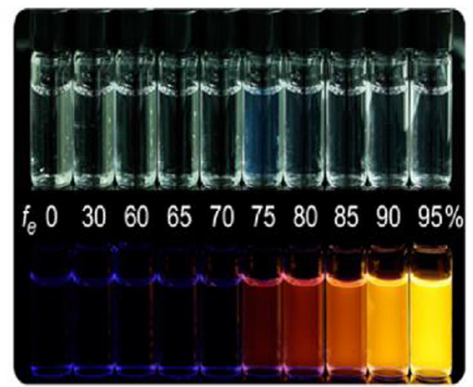

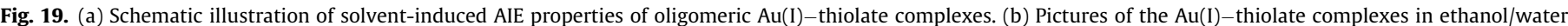

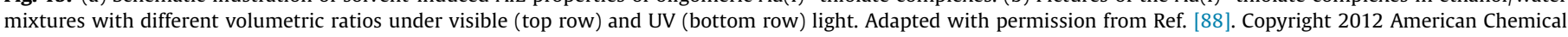
Society.

mal annealing and cooling cycles that influence the $\mathrm{Cu}-\mathrm{Cu}$ distances in the stacks by exploiting the melting of a polymeric matrix.

Oligomeric $\mathrm{Au}(\mathrm{I})$ thiolate complexes containing 10-12 gold atoms and glutathione (a tripeptide containing a thiol and two carboxylic groups) are non-luminescent in aqueous solution and brightly phosphorescent upon solvent or cation-induced aggregation [88] (see Fig. 19). When the fraction of EtOH reached 75\% a weak red phosphorescence appears, which progressively turns into a bright yellow one increasing the EtOH content to 95\% [89]. The authors suggested that this peculiar behavior can arise from the interplay of intracomplex and intercomplex metallophilic interactions and polarity effects. In the same work, it was found that heating up the aqueous solution of oligomeric $\mathrm{Au}(\mathrm{I})$ complexes at $70^{\circ} \mathrm{C}$ for $24 \mathrm{~h}$ resulted in the formation of highly luminescent small (diameter $<2 \mathrm{~nm}$ ) gold nanoclusters composed of an $\mathrm{Au}(0)$ core surrounded by a shell of $\mathrm{Au}(\mathrm{I})$-thiolate oligomeric complexes. The photophysical properties of the nanoclusters are similar to those obtained by solvent induced aggregation. Blue shifted emissions observed upon decreasing the size of the $\mathrm{Au}(0)$ core. This observation, together with the high ratio of $\mathrm{Au}(\mathrm{I})$-thiolate complexes with respect to $\mathrm{Au}(0)$ atoms, prompted the authors to suggest that the observed emission may arise from the AIP effect of the $\mathrm{Au}(\mathrm{I}) \mathrm{com}$ plexes on the $\mathrm{Au}(0)$ core. Accordingly, with the AIP mechanism, the nanocrystals were emissive also in the solid state. AIP effects were observed also for other metal nanoclusters, e.g. $\mathrm{Ag}[90,91]$ and $\mathrm{Cu}$ [92,93].

\subsection{Induction of aggregation induced phosphorescence of organic molecules}

In the previous sections we focused on mechanisms in which a metal containing species was the actual phosphorescent species. However, a few examples have been reported in which a metal complex induces the AIP effect on a nearby purely organic molecule or moiety.

Triangular $\mathrm{Hg}(\mathrm{II})$ pyrazolate complexes are highly planar and present a high affinity to organic $\pi$-extended systems, such as benzene [94]. This property was exploited to form phosphorescent columnar stacks of alternated $\mathrm{Hg}$ (II) complexes and aromatic hydrocarbons (see Fig. 20).

The trinuclear $\mathrm{Hg}(\mathrm{II})$ pyrazolate complex 19 is non-emissive in solution and features a bright red-orange emission in the solid state, due to $\mathrm{Hg}-\mathrm{Hg}$ interactions among the stacked complexes [96]. Upon evaporation of a solution containing the $\mathrm{Hg}$ (II) complex and an aromatic hydrocarbon, phosphorescent solids were obtained in which the two species associate with 1:1 stoichiometry and form alternate columnar assemblies $[95,96]$. The close match between the emission spectra of the solid sample of $\mathbf{1 9}$ and the

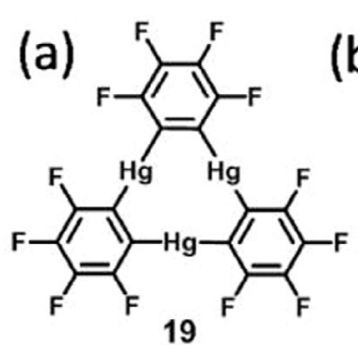

(b)
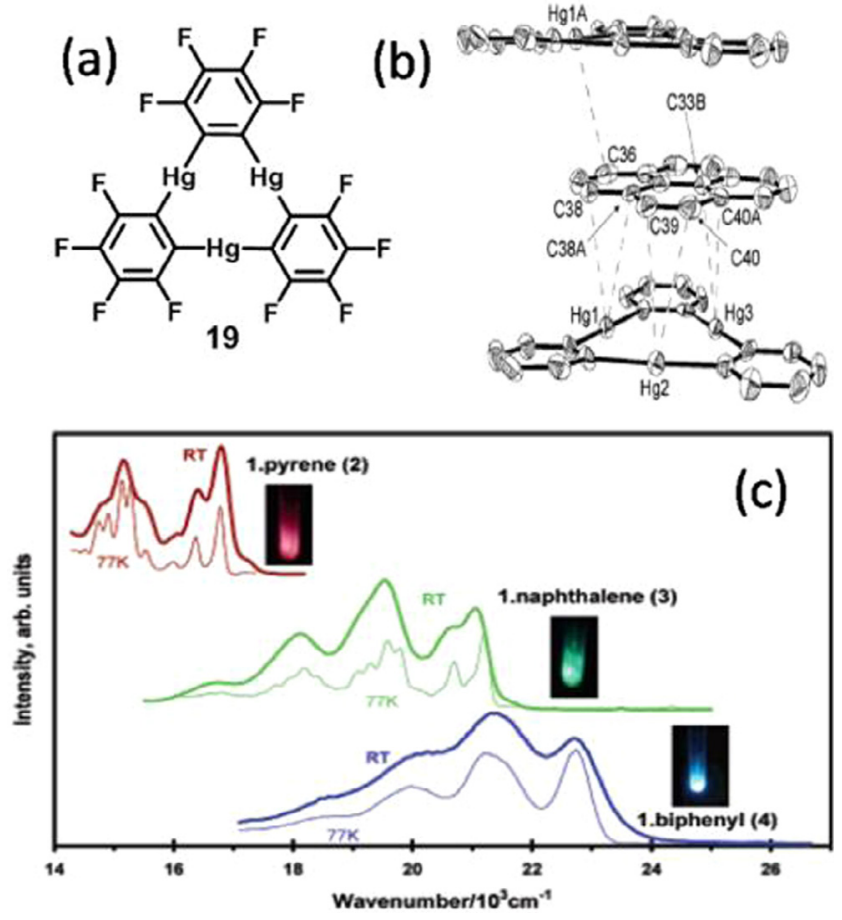

Fig. 20. (a) Formula of a trinuclear $\mathrm{Hg}$ (II) complex. (b) Crystal structure of the columnar stacks formed by complex 19 and pyrene. (c) Phosphorescence spectra of the columnar stacks containing pyrene, naphthalene and biphenyl at $77 \mathrm{~K}$ and room temperature (photos at RT under UV irradiation).Adapted with permission from Ref. [95]. Copyright 2003 American Chemical Society.

phosphorescence of the aromatic hydrocarbons in frozen matrix at $77 \mathrm{~K}$ prompted the authors to assign the emission to the organic molecule. The much shorter lifetimes of the columnar stacks at room temperature with respect to the aromatic hydrocarbons in $77 \mathrm{~K}$ frozen matrix (e.g. about $500 \mu$ s vs $700 \mathrm{~ms}$ for pyrene) were attributed by the authors to the higher rate of the intersystem crossing process induced by the heavy atom effect of $\mathrm{Hg}$ on the aromatic hydrocarbon.

An alternative approach to switch on the phosphorescence of an organic chromophore by metal complexation is reported in Fig. 21 [97]. The hexathiobenzene chromophore (blue part in Fig. 21) is not phosphorescent in fluid solution and becomes highly phosphorescent upon crystallization or rigidification of the matrix [98,99]. Analogously, the terpyridine appended persulfurated chromophore shown in Fig. 21 is non-emissive in solution, but displays a green phosphorescence emission in the solid state $(\Phi=0.02$, $\tau=11.6 \mu \mathrm{s}$ ) due to the restriction of intermolecular motion in the solid state. 


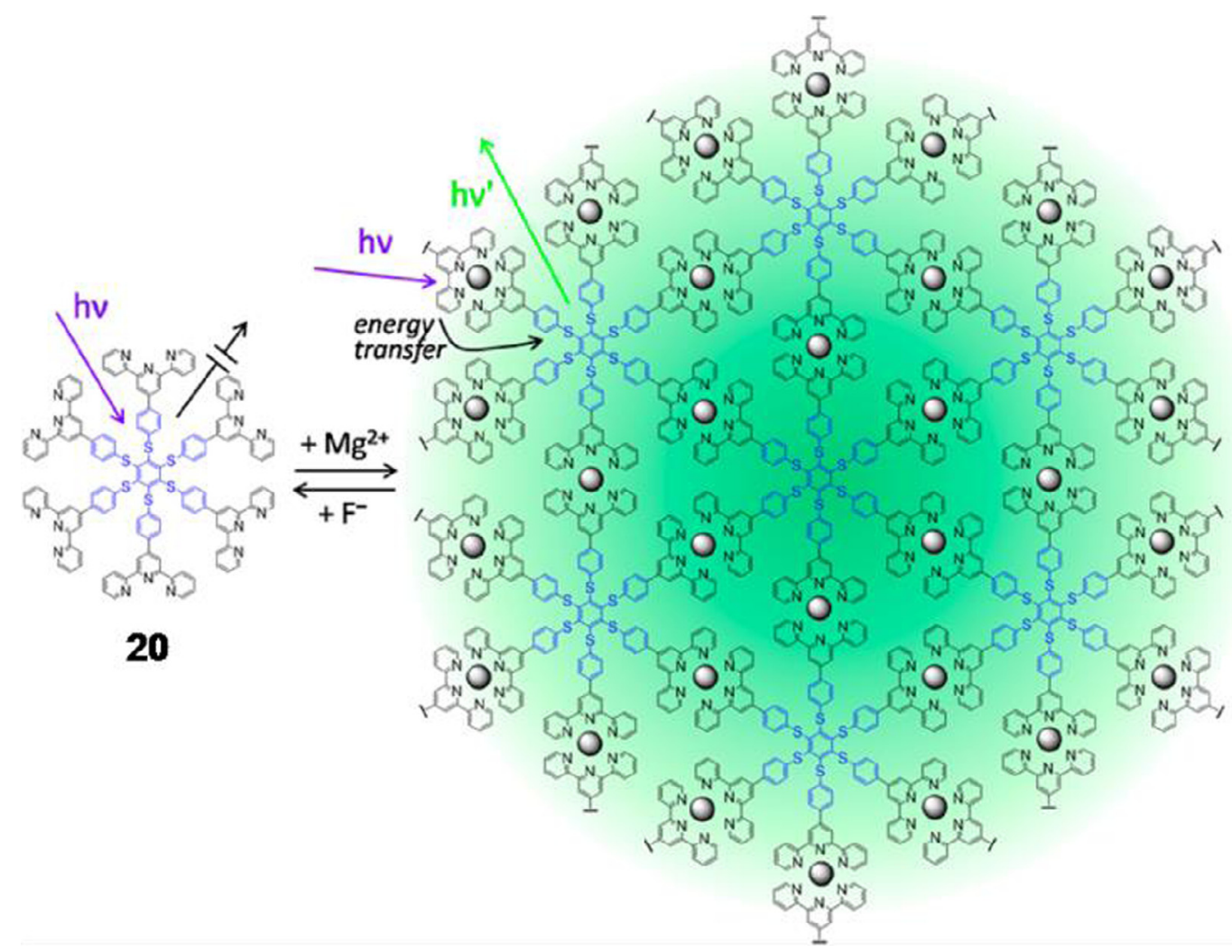

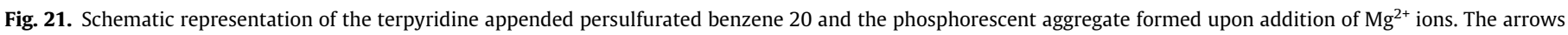
indicate the photophysical processes occurring in the system. Adapted with permission from Ref. [97]. Copyright 2014 American Chemical Society.

Upon addition of $\mathrm{Mg}^{2+}$ to an air-equilibrated THF solution of $\mathbf{2 0}$, a supramolecular polymer is formed (Fig. 21), in which the reduced mobility of the organic moiety is reflected by the appearance of a bright phosphorescence $(\Phi=0.10, \tau=5.3 \mu \mathrm{s})$ with band shape very similar to that of the ligand in the solid state. The polymer formation is confirmed by DLS and AFM analysis: nanoparticles with a diameter of approximately $60 \mathrm{~nm}$ are present. The peculiarity of this system is that, although it contains metal complexes, the metal doesn't play an "active" role in the phosphorescence $\left(\mathrm{Mg}^{2+}\right.$ is unable to induce phosphorescence by heavy atom effect), but acts only as a "rigidifier", while the AIP arises from the organic ligand due to a mechanism of restriction of intermolecular motion. The polymer can be reversibly disassembled by addition of fluoride anions ("off" state). Excitation spectra reveal also that more than $90 \%$ of the light energy absorbed by the Mg complexes is funneled to the AIP emissive persulfurated benzene by energy transfer, thus realizing the first example of light harvesting antenna based on the AIP phenomenon, able to sense both $\mathrm{Mg}^{2+}$ and $\mathrm{F}^{-}$ions.

\section{Conclusions and outlooks}

Phosphorescent materials and devices are usually based on metal complexes rather than on organic chromophores. This is due to the enhanced spin-orbit coupling typical of metal complexes: the presence of a heavy metal ion and, in some cases, of charge-transfer (CT) transitions with a very small energy difference between states of different multiplicity promotes spin-orbit coupling to populate the phosphorescent excited state.

In the last few years, a great attention has been devoted to metal complexes that are weakly or non-phosphorescent in deaerated fluid solution and strongly phosphorescent upon aggregation in solid state or in nanoaggregates dispersed in solution. This phe- nomenon has been named aggregation induced phosphorescence. The present review reports the most relevant examples from a tutorial point of view, divided in two classes on the basis of the AIP mechanisms: (i) aggregation causes a rigidification of the metal complex both in the ground- and in the excited states; (ii) aggregation brings metal complexes in close proximity, thus facilitating metallophilic interactions. The last section deals with a special case in which phosphorescence of organic chromophores is switched on upon metal complexation.

The mechanism (i) is shared with AIP organic chromophores, while mechanism (ii) is typical of metal complexes. Metallophilic interactions are strongly dependent on the complex geometry: square planar or linear geometry enables a close contact between metal centers and thus favors metallophilic interactions, while in octahedral geometry, the metal center is buried within the ligand cage.

The great attention that AIP has recently attracted is mainly related to the fact that phosphorescent metal complexes are mostly used in solid-state devices, like OLEDs. Beyond this, a stimulating and emerging field of research is that of luminescent sensors, in which phosphorescence is switched on by the addition of an analyte, which causes aggregation or modify the crystal structure. Some examples of vapoluminescent compounds and sensing in living cells have been presented in this review, but certainly much more research is expected in the future.

The main challenge, at the moment, is to make a clear correlation between phosphorescent properties and structure, particularly in the case of nanostructures dispersed in solution since luminescence and structural characterizations (SEM, TEM, X-ray diffraction) are made under different experimental conditions. Therefore, new studies in this direction are expected to provide a clearer correlation and to drive the design of AIP metal complexes with new applications. 


\section{Acknowledgments}

We gratefully acknowledge the European Commission ERC Starting Grant (PhotoSi, 278912).

\section{References}

[1] G.N. Lewis, D. Lipkin, T.T. Magel, Reversible photochemical processes in rigid media. A study of the phosphorescent state, J. Am. Chem. Soc. 63 (1941) 30053018, http://dx.doi.org/10.1021/ja01856a043.

[2] G.N. Lewis, M. Calvin, Paramagnetism of the phosphorescent state, J. Am. Chem. Soc. 67 (1945) 1232-1233, http://dx.doi.org/10.1021/ja01223a513.

[3] A. Buckley (Ed.), Organic Light-Emitting Diodes (OLEDs): Materials, Devices and Applications, Woodhead Publishing Limited, Cambridge, 2013.

[4] R.D. Costa, E. Ortí, H.J. Bolink, F. Monti, G. Accorsi, N. Armaroli, Luminescent ionic transition-metal complexes for light-emitting electrochemical cells, Angew. Chem. Int. Ed. 51 (2012) 8178-8211, http://dx.doi.org/10.1002/ anie.201201471.

[5] M. Schäferling, The art of fluorescence imaging with chemical sensors, Angew. Chem. Int. Ed. 51 (2012) 3532-3554, http://dx.doi.org/10.1002/ anie.201105459.

[6] V. Balzani, P. Ceroni, A. Juris, Photochemistry and Photophysics: Concepts, Research, Applications, John Wiley \& Sons, 2014.

[7] V. Balzani, S. Campagna (Eds.), Photochemistry and photophysics of coordination compounds II, Top. Curr. Chem. 281 (2007) 1-309.

[8] V. Balzani, S. Campagna (Eds.), Photochemistry and photophysics of coordination compounds I, Top. Curr. Chem. 280 (2007) 1-255.

[9] K. Kalyanasundaram, Photochemistry of Polypyridine and Porphyrin Complexes, Academic Press, London, 1992.

[10] N.A.P. Kane-Maguire, Photochemistry and photophysics of coordination compounds: chromium, Top. Curr. Chem. 280 (2007) 37-67.

[11] N.J. Turro, V. Ramamurthy, J.C. Scaiano, Modern Molecular Photochemistry of Organic Molecules, University Science Books, Sausalito, 2010.

[12] P. Klán, J. Wirz, Photochemistry of Organic Compounds: From Concepts to Practice, Wiley, Chichester, 2009.

[13] V.W.-W. Yam, V.K.-M. Au, S.Y.-L. Leung, Light-emitting self-assembled materials based on d 8 and d 10 transition metal complexes, Chem. Rev. 115 (2015) 7589-7728, http://dx.doi.org/10.1021/acs.chemrev.5b00074.

[14] J. Kuwabara, Y. Ogawa, A. Taketoshi, T. Kanbara, Enhancement of the photoluminescence of a thioamide-based pincer palladium complex in the crystalline state, J. Organomet. Chem. 696 (2011) 1289-1293, http://dx.doi. org/10.1016/j.jorganchem.2010.12.037.

[15] Y.-W. Dong, R.-Q. Fan, X.-M. Wang, P. Wang, H.-J. Zhang, L.-G. Wei, Y. Song, X. Du, W. Chen, Y.-L. Yang, Topological evolution in mercury(II) schiff base complexes tuned through alkyl substitution - synthesis, solid-state structures, and aggregation-induced emission properties, Eur. J. Inorg. Chem. (2016) 3598-3610, http://dx.doi.org/10.1002/ejic.201600231.

[16] O. Toma, M. Allain, F. Meinardi, A. Forni, C. Botta, N. Mercier, Bismuth-based coordination polymers with efficient aggregation-induced phosphorescence and reversible mechanochromic luminescence, Angew. Chem. Int. Ed. 55 (2016) 7998-8002, http://dx.doi.org/10.1002/anie.201602602.

[17] C. Zhu, S. Li, M. Luo, X. Zhou, Y. Niu, M. Lin, J. Zhu, Z. Cao, X. Lu, T. Wen, Z. Xie, P. V.R. Schleyer, H. Xia, Stabilization of anti-aromatic and strained fivemembered rings with a transition metal, Nat. Chem. 5 (2013) 698-703, http://dx.doi.org/10.1038/nchem.1690.

[18] Y. Chen, W.C. Xu, J.F. Kou, B. Le Yu, X.H. Wei, H. Chao, L.N. Ji, Aggregationinduced emission of ruthenium(II) polypyridyl complex $\left[\operatorname{Ru}(\text { bpy })_{2}(\text { pzta })\right]^{2+}$ Inorg. Chem. Commun. 13 (2010) 1140-1143, http://dx.doi.org/10.1016/j. inoche.2010.06.029.

[19] P. Ceroni, Design of phosphorescent organic molecules: old concepts under a new light, Chem 1 (2016) 524-526, http://dx.doi.org/10.1016/j. chempr.2016.09.011.

[20] S. Mukherjee, P. Thilagar, Recent advances in purely organic phosphorescent materials, Chem. Commun. 51 (2015) 10988-11003, http://dx.doi.org/ 10.1039/C5CC03114A.

[21] J. Mei, N.L.C. Leung, R.T.K. Kwok, J.W.Y. Lam, B.Z. Tang, Aggregation-induced emission: together we shine, united we soar!, Chem Rev. 115 (2015) 1171811940, http://dx.doi.org/10.1021/acs.chemrev.5b00263.

[22] N. Armaroli, G. Accorsi, F. Cardinali, A. Listorti, Photochemistry and photophysics of coordination compounds: copper, Top. Curr. Chem. 280 (2007) 69-115.

[23] A. Barbieri, G. Accorsi, N. Armaroli, Luminescent complexes beyond the platinum group: the d10 avenue, Chem. Commun. (2008) 2185-2193, http:// dx.doi.org/10.1039/b716650h.

[24] F. Dumur, Recent advances in organic light-emitting devices comprising copper complexes: a realistic approach for low-cost and highly emissive devices?, Org Electron. Phys. Mater. Appl. 21 (2015) 27-39, http://dx.doi.org/ 10.1016/j.orgel.2015.02.026.

[25] N. Armaroli, Photoactive mono- and polynuclear $\mathrm{Cu}(\mathrm{I})$-phenanthrolines. A viable alternative to Ru(II)-polypyridines?, Chem Soc. Rev. 30 (2001) 113-124, http://dx.doi.org/10.1039/b000703j.

[26] D.V. Scaltrito, D.W. Thompson, J.A. O’Callaghan, G.J. Meyer, MLCT excited states of cuprous bis-phenanthroline coordination compounds, Coord
Chem. Rev. 208 (2000) 243-266, http://dx.doi.org/10.1016/s0010-8545(00) 00309-X.

[27] X.L. Xin, M. Chen, Y.B. Ai, F.L. Yang, X.L. Li, F. Li, Aggregation-induced emissive copper(I) complexes for living cell imaging, Inorg. Chem. 53 (2014) 29222931, http://dx.doi.org/10.1021/ic402685u.

[28] S. Zink, D.M. Bächle, M. Baumann, T. Nieger, M. Kühn, M. Wang, C. Klopper, W. Monkowius, U. Hofbeck, T. Yersin, H. Bräse, Synthesis, structure, and characterization of dinuclear copper (i) halide complexes with $\mathrm{P}^{\wedge} \mathrm{N}$ ligands featuring exciting photoluminescence properties, Inorg. Chem. 52 (2013) 2292-2305, http://dx.doi.org/10.1021/ic300979c.

[29] D.G. Cuttell, S.-M. Kuang, P.E. Fanwick, D.R. McMillin, R.A. Walton, Simple Cu(I) complexes with unprecedented excited-state lifetimes, J. Am. Chem. Soc. 124 (2002) 6-7, http://dx.doi.org/10.1021/ja012247h.

[30] M. Vitale, P.C. Ford, Luminescent mixed ligand copper(I) clusters (CuI)n(L)m ( $\mathrm{L}=$ pyridine, piperidine): thermodynamic control of molecular and supramolecular species, Coord. Chem. Rev. 219 (2001) 3-16, http://dx.doi. org/10.1016/S0010-8545(00)00414-8.

[31] J.R. Kirchhoff, R.E. Gamache, M.W. Blaskie, A.A. Del Paggio, R.K. Lengel, D.R. McMillin, Temperature dependence of luminescence from $\mathrm{Cu}(\mathrm{NN})^{2+}$ systems in fluid solution. Evidence for the participation of two excited states, Inorg. Chem. 22 (1983) 2380-2384, http://dx.doi.org/10.1021/ic00159a008.

[32] M.J. Leitl, D.M. Zink, A. Schinabeck, T. Baumann, D. Volz, H. Yersin, Copper(I) complexes for thermally activated delayed fluorescence: from photophysical to device properties, Top. Curr. Chem. 374 (2016) 1-34, http://dx.doi.org/ 10.1007/s41061-016-0019-1.

[33] O. Benito, A. Fargues, A. Garcia, S. Maron, T. Gacoin, J.P. Boilot, S. Perruchas, F. Camerel, Photoactive hybrid gelators based on a luminescent inorganic $[\mathrm{Cu}$ 4I4] cluster core, Chem. Eur. J. 19 (2013) 15831-15835, http://dx.doi.org/ 10.1002/chem.201303567.

[34] K.K.W. Lo, K.Y. Zhang, S.P.Y. Li, Recent exploitation of luminescent rhenium(I) tricarbonyl polypyridine complexes as biomolecular and cellular probes, Eur. J. Inorg. Chem. (2011) 3551-3568, http://dx.doi.org/10.1002/ejic.201100469.

[35] D. Striplin, G. Crosby, Photophysical investigations of rhenium(I)Cl(CO)3 (phenanthroline) complexes, Coord. Chem. Rev. 211 (2001) 163-175, http:// dx.doi.org/10.1016/S0010-8545(00)00277-0.

[36] S.S. Sun, A.J. Lees, Self-assembly triangular and square rhenium(I) tricarbonyl complexes: a comprehensive study of their preparation, electrochemistry, photophysics, photochemistry, and host-guest properties, J. Am. Chem. Soc. 122 (2000) 8956-8967, http://dx.doi.org/10.1021/ja001677p.

[37] G.-W. Zhao, J.-H. Zhao, Y.-X. Hu, D.-Y. Zhang, X. Li, Recent advances of neutral rhenium(I) tricarbonyl complexes for application in organic light-emitting diodes, Synth. Met. 212 (2016) 131-141, http://dx.doi.org/10.1016/j. synthmet.2015.12.014

[38] D. Donghi, G. D’Alfonso, M. Mauro, M. Panigati, P. Mercandelli, A. Sironi, P. Mussini, L. D'Alfonso, A new class of luminescent tricarbonyl rhenium(I) complexes containing bridging 1,2-diazine ligands: electrochemical, photophysical, and computational characterization, Inorg. Chem. 47 (2008) 4243-4255, http://dx.doi.org/10.1021/ic7023692.

[39] B. Manimaran, P. Thanasekaran, T. Rajendran, R.J. Lin, I.J. Chang, G.H. Lee, S.M. Peng, S. Rajagopal, K.L. Lu, Luminescence enhancement induced by aggregation of alkoxy-bridged rhenium(I) molecular rectangles, Inorg. Chem. 41 (2002) 5323-5325, http://dx.doi.org/10.1021/ic020364n.

[40] C. Cebrián, M. Natali, D. Villa, M. Panigati, M. Mauro, G. D’Alfonso, L. De Cola, Luminescent supramolecular soft nanostructures from amphiphilic dinuclear $\operatorname{Re}(\mathrm{I})$ complexes, Nanoscale 7 (2015) 12000-12009, http://dx.doi.org/10.1039/ C5NR01668A.

[41] E. Quartapelle Procopio, M. Mauro, M. Panigati, D. Donghi, P. Mercandelli, A Sironi, G. D'Alfonso, L. De Cola, Highly emitting concomitant polymorphic crystals of a dinuclear rhenium complex, J. Am. Chem. Soc. 132 (2010) 1439714399, http://dx.doi.org/10.1021/ja106772v.

[42] M.S. Lowry, S. Bernhard, Synthetically tailored excited states: phosphorescent, cyclometalated iridium(III) complexes and their applications, Chem. Eur. J. 12 (2006) 7970-7977, http://dx.doi.org/10.1002/chem.200600618.

[43] I.M. Dixon, J.-P. Collin, J.-P. Sauvage, L. Flamigni, S. Encinas, F. Barigelletti, A family of luminescent coordination compounds: iridium(iii) polyimine complexes, Chem. Soc. Rev. 29 (2000) 385-391, http://dx.doi.org/10.1039/ b000704h.

[44] Y. You, S.Y. Park, Phosphorescent iridium(III) complexes: toward high phosphorescence quantum efficiency through ligand control, Dalton Trans. 8 (2009) 1267-1282, http://dx.doi.org/10.1039/B812281D.

[45] Y. You, W. Nam, Photofunctional triplet excited states of cyclometalated Ir(III) complexes: beyond electroluminescence, Chem. Soc. Rev. 41 (2012) 70617084, http://dx.doi.org/10.1039/c2cs35171d.

[46] C. Ulbricht, B. Beyer, C. Friebe, A. Winter, U.S. Schubert, Recent developments in the application of phosphorescent iridium(III) complex systems, Adv. Mater. 21 (2009) 4418-4441, http://dx.doi.org/10.1002/adma.200803537.

[47] Q. Zhao, L. Li, F. Li, M. Yu, Z. Liu, T. Yi, C. Huang, Aggregation-induced phosphorescent emission (AIPE) of iridium(III) complexes, Chem. Commun. (2008) 685-687, http://dx.doi.org/10.1039/B712416C.

[48] H. Wu, T. Yang, Q. Zhao, J. Zhou, C. Li, F. Li, A cyclometalated iridium(III) complex with enhanced phosphorescence emission in the solid state (EPESS): synthesis, characterization and its application in bioimaging, Dalton Trans. 40 (2011) 1969-1976, http://dx.doi.org/10.1039/c0dt01366h.

[49] Y. You, H.S. Huh, K.S. Kim, S.W. Lee, D. Kim, S.Y. Park, Comment on 'Aggregation-induced phosphorescent emission (AIPE) of iridium (III) 
complexes': origin of the enhanced phosphorescence, Chem. Commun. (2008) 3998-4000, http://dx.doi.org/10.1039/b806541a.

[50] K. Huang, H. Wu, M. Shi, F. Li, T. Yi, C. Huang, Reply to comment on "aggregation-induced phosphorescent emission (AIPE) of iridium(III) complexes": origin of the enhanced phosphorescence, Chem. Commun. (2009) 1243-1245, http://dx.doi.org/10.1039/b816056b.

[51] A.J. Howarth, R. Patia, D.L. Davies, F. Lelj, M.O. Wolf, K. Singh, Elucidating the origin of enhanced phosphorescence emission in the solid state (EPESS) in cyclometallated iridium complexes, Eur. J. Inorg. Chem. (2014) 3657-3664, http://dx.doi.org/10.1002/ejic.201402495.

[52] M. Mauro, G. De Paoli, M. Otter, D. Donghi, G. D’Alfonso, L. De Cola, Aggregation induced colour change for phosphorescent $\operatorname{Ir}(\mathrm{III})$ complex-based anionic surfactants, Dalton Trans. 40 (2011) 12106-12116, http://dx.doi.org/ 10.1039/c1dt10876j.

[53] G. Shan, H. Li, J. Qin, D. Zhu, Y. Liao, Z.-M. Su, Piezochromic luminescent (PCL) behavior and aggregation-induced emission (AIE) property of a new cationic iridium(III) complex, Dalton Trans. 41 (2012) 9590, http://dx.doi.org/10.1039/ c2dt31013a.

[54] G.-G. Shan, D.-X. Zhu, H.-B. Li, P. Li, Z.-M. Su, Y, Liao, Creation of cationic iridium(III) complexes with aggregation-induced phosphorescent emission (AIPE) properties by increasing rotation groups on carbazole peripheries, Dalton Trans. 40 (2011) 2947-2953, http://dx.doi.org/10.1039/c0dt01559h.

[55] G.-G. Shan, H.-B. Li, H.-Z. Sun, D.-X. Zhu, H.-T. Cao, Z.-M. Su, Controllable synthesis of iridium(III)-based aggregation-induced emission and/or piezochromic luminescence phosphors by simply adjusting the substitution on ancillary ligands, J. Mater. Chem. C 1 (2013) 1440-1449, http://dx.doi.org/ 10.1039/C2TC00558A.

[56] P. Alam, C. Climent, G. Kaur, D. Casanova, A. Roy Choudhury, A. Gupta, P. Alemany, I.R. Laskar, Exploring the origin of "Aggregation-Induced Emission" activity and mechanofluorochromism in organometallic iridium(III) cationic complexes: influence of counterions, Cryst. Growth Des. 16 (2016) 5738-5752, http://dx.doi.org/10.1021/acs.cgd.6b00810, acs.cgd.6b00810.

[57] A.G. Williams, Photochemistry and photophysics of coordination compounds: platinum, Top. Curr. Chem. 281 (2007) 205-268.

[58] F.N. Castellano, I.E. Pomestchenko, E. Shikhova, F. Hua, M.L. Muro, N. Rajapakse, Photophysics in bipyridyl and terpyridyl platinum (II) acetylides, Coord. Chem. Rev. 250 (2006) 1819-1828, http://dx.doi.org/10.1016/j. ccr.2006.03.007.

[59] S.-W. Lai, C.M. Che, Luminescent cyclometalated diimine platinum (II) complexes: photophysical studies and applications, in: Transition Metal and Rare Earth Compounds, Springer, Berlin Heidelberg, 2004, pp. 27-63, http://dx. doi.org/10.1007/b96859.

[60] R. Mcmillin, J.J. Moore, Luminescence that lasts from Pt(trpy)Cl derivatives, Coord. Chem. Rev. 229 (2002) 113-121.

[61] J.A.G. Williams, The coordination chemistry of dipyridylbenzene: N-deficient terpyridine or panacea for brightly luminescent metal complexes?, Chem Soc. Rev. 38 (2009) 1783-1801, http://dx.doi.org/10.1039/B804434C.

[62] K.M.C. Wong, V.W.W. Yam, Luminescence platinum(II) terpyridyl complexesFrom fundamental studies to sensory functions, Coord. Chem. Rev. 251 (2007) 2477-2488, http://dx.doi.org/10.1016/j.ccr.2007.02.003.

[63] S. Liu, H. Sun, Y. Ma, S. Ye, X. Liu, X. Zhou, X. Mou, L. Wang, Q. Zhao, W. Huang Rational design of metallophosphors with tunable aggregation-induced phosphorescent emission and their promising applications in time-resolved luminescence assay and targeted luminescence imaging of cancer cells, J. Mater. Chem. 22 (2012) 22167-22173, http://dx.doi.org/10.1039/c2jm34512a.

[64] R. Pattacini, C. Giansante, P. Ceroni, M. Maestri, P. Braunstein, Phosphinoaminothiazoline platinum(II) and platinum(II)/gold(I) complexes: structural, chemical and vapoluminescent properties, Chem. Eur. J. 13 (2007) 1011710128, http://dx.doi.org/10.1002/chem.200701081.

[65] M. Mauro, A. Aliprandi, D. Septiadi, N.S. Kehr, L. De Cola, When self-assembly meets biology: luminescent platinum complexes for imaging applications, Chem. Soc. Rev. 43 (2014) 4144-4166, http://dx.doi.org/10.1039/c3cs60453e.

[66] J.S. Miller (Ed.), Extended Linear Chain Compounds, Plenum Press, New York, 1982

[67] H. Keller (Ed.), Chemistry and Physics of One-dimensional Metals, Plenum Press, New York, 1977.

[68] A. Aliprandi, D. Genovese, M. Mauro, L. De Cola, Recent advances in phosphorescent $\mathrm{Pt}(\mathrm{II})$ complexes featuring metallophilic interactions: properties and applications, Chem. Lett. 44 (2015) 1152-1169, http://dx.doi. org/10.1246/cl.150592.

[69] J.A. Bailey, M.G. Hill, R.E. Marsh, V.M. Miskowski, W.P. Schaefer, H.B. Gray, Electronic spectroscopy of chloro(terpyridine)platinum(II), Inorg. Chem. 34 (1995) 4591-4599, http://dx.doi.org/10.1021/ic00122a015.

[70] C. Po, A.Y.Y. Tam, K.M.C. Wong, V.W.W. Yam, Supramolecular self-assembly of amphiphilic anionic platinum(II) complexes: a correlation between spectroscopic and morphological properties, J. Am. Chem. Soc. 133 (2011) 12136-12143, http://dx.doi.org/10.1021/ja203920w.

[71] K. Wang, M. Haga, H. Monjushiro, M. Akiba, Y. Sasaki, Luminescent Langmuir Blodgett Films of Platinum (II) Complex [Pt (L18) Cl ](PF 6) (L18) 2, 6-Bis (1-octadecylbenzimidazol-2-yl) pyridine), Inorg. Chem. 39 (2000) 4022-4028.

[72] L.J. Grove, J.M. Rennekamp, H. Jude, W.B. Connick, A new class of platinum (II) vapochromic salts, J. Am. Chem. Soc. 126 (2004) 1594-1595, http://dx.doi.org/ $10.1021 / \mathrm{ja037783 \textrm {j }}$.

[73] A. Aliprandi, M. Mauro, L. De Cola, Controlling and imaging biomimetic selfassembly, Nat. Chem. 8 (2016) 2-7, http://dx.doi.org/10.1038/nchem.2383.
[74] T. Ikeda, M. Takayama, J. Kumar, T. Kawai, T. Haino, Novel helical assembly of a $\mathrm{Pt}(\mathrm{ii})$ phenylbipyridine complex directed by metal-metal interaction and aggregation-induced circularly polarized emission, Dalton Trans. 44 (2015) 13156-13162, http://dx.doi.org/10.1039/C5DT01284H.

[75] V.N. Kozhevnikov, B. Donnio, D.W. Bruce, Phosphorescent, terdentate, liquidcrystalline complexes of platinum(II): stimulus-dependent emission, Angew. Chem. Int. Ed. 47 (2008) 6286-6289, http://dx.doi.org/10.1002/ anie.200802101.

[76] V.W.-W. Yam, E.C.-C. Cheng, Photochemistry and photophysics of coordination compounds: gold, Top. Curr. Chem. 281 (2007) 269-309.

[77] J.P. Fackler, Z. Assefa, J.M. Forward, R.J. Staples, Excited states of Gold (I) compounds, Metal-based Drugs 1 (1994) 459-466.

[78] X. He, V.W.W. Yam, Luminescent gold(I) complexes for chemosensing, Coord. Chem. Rev. 255 (2011) 2111-2123, http://dx.doi.org/10.1016/j. ccr.2011.02.003.

[79] V.W.-W. Yam, K.K.-W. Lo, Luminescent polynuclear d10 metal complexes, Chem. Soc. Rev. 28 (1999) 323-334, http://dx.doi.org/10.1039/a804249g.

[80] W.P. To, K.T. Chan, G.S.M. Tong, C. Ma, W.M. Kwok, X. Guan, K.H. Low, C.M. Che, Strongly luminescent gold(III) complexes with long-lived excited states: High emission quantum yields, energy up-conversion, and nonlinear optica properties, Angew. Chem. Int. Ed. 52 (2013) 6648-6652, http://dx.doi.org/ 10.1002/anie.201301149.

[81] H. Schmidbaur, A. Schier, A briefing on aurophilicity, Chem. Soc. Rev. 37 (2008) 1931-1951, http://dx.doi.org/10.1039/b708845k.

[82] H. Schmidbaur, Ludwig Mond lecture. High-carat gold compounds, Chem. Soc Rev. 24 (1995) 391-400.

[83] K.S. Pitzer, Relativistic effects on chemical properties, Acc. Chem. Res. 12 (1979) 271-276, http://dx.doi.org/10.1021/ar50079a001.

[84] J. Liang, Z. Chen, L. Xu, J. Wang, J. Yin, G.-A. Yu, Z.-N. Chen, S.H. Liu, Aggregation-induced emission-active gold(i) complexes with multi-stimul luminescence switching, J. Mater. Chem. C 2 (2014) 2243-2250, http://dx.doi. org/10.1039/c3tc31638f.

[85] A. Kishimura, T. Yamashita, T. Aida, Phosphorescent organogels via "metallophilic" interactions for reversible RGB-color switching, J. Am. Chem. Soc. 127 (2005) 179-183, http://dx.doi.org/10.1021/ja0441007.

86] M. Enomoto, A. Kishimura, T. Aida, Coordination metallacycles of an achira dendron self-assemble via metal-metal interaction to form luminescent superhelical fibers, J. Am. Chem. Soc. 123 (2001) 5608-5609, http://dx.doi. org/10.1021/ja010426t.

87] A. Kishimura, T. Yamashita, K. Yamaguchi, T. Aida, Rewritable phosphorescent paper by the control of competing kinetic and thermodynamic self-assembling events, Nat. Mater. 4 (2005) 546-549, http://dx.doi.org/10.1038/nmat1401.

[88] Z. Luo, X. Yuan, Y. Yu, Q. Zhang, D.T. Leong, J.Y. Lee, J. Xie, From aggregationinduced emission of $\mathrm{Au}(\mathrm{I})$-thiolate complexes to ultrabright $\mathrm{Au}(0) @ \mathrm{Au}(\mathrm{I})$ thiolate core-shell nanoclusters, J. Am. Chem. Soc. 134 (2012) 16662-16670 http://dx.doi.org/10.1021/ja306199p.

[89] N. Goswami, Q. Yao, Z Luo, J. Li, T. Chen, J. Xie, Luminescent metal nanoclusters with aggregation-induced emission, J. Phys. Chem. Lett. 7 (2016) 962-975 http://dx.doi.org/10.1021/acs.jpclett.5b02765.

[90] Q. Yao, Z. Luo, X. Yuan, Y. Yu, C. Zhang, J. Xie, J.Y. Lee, Assembly of nanoions via electrostatic interactions: ion-like behavior of charged noble metal nanoclusters, Sci. Rep. 4 (2014) 1-8, http://dx.doi.org/10.1038/srep03848.

[91] X. Jia, J. Li, E. Wang, Supramolecular self-assembly of morphology-dependent luminescent Ag nanoclusters, Chem. Commun. 50 (2014) 9565-9568, http:// dx.doi.org/10.1039/c4cc03913k.

[92] X. Jia, J. Li, E. Wang, Cu nanoclusters with aggregation induced emission enhancement, Small 9 (2013) 3873-3879, http://dx.doi.org/10.1002/ smll.201300896.

[93] Z. Wu, J. Liu, Y. Gao, H. Liu, T. Li, H. Zou, Z. Wang, K. Zhang, Y. Wang, H. Zhang, B. Yang, Assembly-induced enhancement of $\mathrm{Cu}$ nanoclusters luminescence with mechanochromic property, J. Am. Chem. Soc. 137 (2015) 12906-12913, http://dx.doi.org/10.1021/jacs.5b06550.

[94] M. Tsunoda, P. Gabbai, $\mu 6-\eta 2: \eta 2: \eta 2: \eta 2: \eta 2: \eta 2$ as a new bonding mode for benzene, J. Am. Chem. Soc. 122 (2000) 8335-8336.

[95] M.A. Omary, R.M. Kassab, M.R. Haneline, O. Elbjeirami, F.P. Gabbai, Enhancement of the phosphorescence of organic luminophores upon interaction with a mercury trifunctional Lewis acid, Inorg. Chem. 42 (2003) 2176-2178, http://dx.doi.org/10.1021/ic034066h.

[96] M.R. Haneline, M. Tsunoda, F.P. Gabbai, П-complexation of biphenyl, naphthalene, and triphenylene to trimeric perfluoro-ortho-phenylene mercury. Formation of extended binary stacks with unusual luminescent properties, J. Am. Chem. Soc. 124 (2002) 3737-3742, http://dx.doi.org/ $10.1021 / \mathrm{ja} 0166794$.

[97] A. Fermi, G. Bergamini, M. Roy, M. Gingras, P. Ceroni, Turn-on phosphorescence by metal coordination to a multivalent terpyridine ligand: a new paradigm for luminescent sensors, J. Am. Chem. Soc. 136 (2014) 63956400.

[98] A. Fermi, G. Bergamini, R. Peresutti, E. Marchi, M. Roy, P. Ceroni, M. Gingras, Molecular asterisks with a persulfurated benzene core are among the strongest organic phosphorescent emitters in the solid state, Dyes Pigments 110 (2014) 113-122, http://dx.doi.org/10.1016/j.dyepig.2014.04.036.

[99] G. Bergamini, A. Fermi, C. Botta, U. Giovanella, S. Di Motta, F. Negri, R. Peresutti, M. Gingras, P. Ceroni, A persulfurated benzene molecule exhibits outstanding phosphorescence in rigid environments: from computational study to organic nanocrystals and OLED applications, J. Mater. Chem. C 1 (2013) 2717-2724 http://dx.doi.org/10.1039/C3TC00878A. 